\title{
Review Article \\ Differential Role of Adipose Tissues in Obesity and Related Metabolic and Vascular Complications
}

\author{
Almudena Gómez-Hernández, ${ }^{1,2,3}$ Nuria Beneit, ${ }^{1,2,3}$ \\ Sabela Díaz-Castroverde, ${ }^{1,2,3}$ and Óscar Escribano ${ }^{1,2,3}$ \\ ${ }^{1}$ Biochemistry and Molecular Biology Department, School of Pharmacy, Complutense University of Madrid, Madrid, Spain \\ ${ }^{2}$ CIBER of Diabetes and Associated Metabolic Diseases, Madrid, Spain \\ ${ }^{3}$ Instituto de Investigación Sanitaria Hospital Clínico San Carlos, IdISSC, Instituto de Salud Carlos III, Madrid, Spain
}

Correspondence should be addressed to Almudena Gómez-Hernández; algomezh@ucm.es and Óscar Escribano; oescriba@ucm.es

Received 15 May 2016; Revised 19 July 2016; Accepted 4 August 2016

Academic Editor: Kristin Eckardt

Copyright (C) 2016 Almudena Gómez-Hernández et al. This is an open access article distributed under the Creative Commons Attribution License, which permits unrestricted use, distribution, and reproduction in any medium, provided the original work is properly cited.

\begin{abstract}
This review focuses on the contribution of white, brown, and perivascular adipose tissues to the pathophysiology of obesity and its associated metabolic and vascular complications. Weight gain in obesity generates excess of fat, usually visceral fat, and activates the inflammatory response in the adipocytes and then in other tissues such as liver. Therefore, low systemic inflammation responsible for insulin resistance contributes to atherosclerotic process. Furthermore, an inverse relationship between body mass index and brown adipose tissue activity has been described. For these reasons, in recent years, in order to combat obesity and its related complications, as a complement to conventional treatments, a new insight is focusing on the role of the thermogenic function of brown and perivascular adipose tissues as a promising therapy in humans. These lines of knowledge are focused on the design of new drugs, or other approaches, in order to increase the mass and/or activity of brown adipose tissue or the browning process of beige cells from white adipose tissue. These new treatments may contribute not only to reduce obesity but also to prevent highly prevalent complications such as type 2 diabetes and other vascular alterations, such as hypertension or atherosclerosis.
\end{abstract}

\section{Introduction}

Obesity is a multifactorial chronic disease with an increased incidence in developed countries over the last decades. Nowadays, it represents a worldwide epidemic [1]; in 2014, $39 \%$ of adults older than 18 years showed overweight, and $13 \%$ were obese. Obesity is a huge public health problem due to the associated risk with developing other diseases [2]. In this sense, $44 \%$ of diabetes cases worldwide, $23 \%$ of ischemic heart disease, and $7-41 \%$ of certain cancers are attributable to overweight and obesity. This occurs, at least partially, because of the obesity-induced insulin resistance and the fact that adipose tissue is not only an energy reservoir but also a secretory endocrine organ of cytokines, hormones, and proteins that affect the functionality of cells and tissues all over the body [3].

In mammals, the adipose tissue is composed of at least two kinds of adipose tissue, the white adipose tissue (WAT) and the brown adipose tissue (BAT) which have different morphology, distribution, gene expression, and function. WAT is the main energy reservoir and secretes a huge number of hormones and cytokines that regulate metabolism and insulin resistance $[3,4]$. The development of obesity depends not only on the balance between food intake and energy expenditure but also on the balance between white adipose tissue, as the main energy reservoir, and brown adipose tissue, specialized in energy expenditure through nonshivering thermogenesis via the mitochondrial uncoupling protein 1 (UCP-1). In addition, BAT could affect body metabolism and alter insulin sensitivity $[5,6]$ as well as modifying the susceptibility to develop obesity [7]. Moreover, in this review, we also analyze the role of perivascular adipose tissue (PVAT) in obesity and mainly its action in the associated vascular complications. This tissue is located around the arteries and other systemic vessels and depending on the vascular bed 
may have more or less characteristics of white or brown adipose tissue.

\section{Differential Morphology, Innervation, and Distribution of Adipose Tissues}

2.1. WAT. Adipocyte from WAT has a variable shape, although it is classically spherical sized between 25 and $200 \mu \mathrm{m}$. In addition, it has a peripheral and flat nucleus with a thin cytoplasm that contains a single large lipid drop, which occupies $90 \%$ of the cell volume. It presents few mitochondria and a small smooth and rough endoplasmic reticulum. WAT is composed of adipocytes that are held together by a poorly vascularized and innervated connective tissue [8]. Sympathetic innervation has been described in WAT, although relatively sparse compared to BAT [9]. As occurs in BAT, WAT parasympathetic innervation is controversial and, at the moment, there is a lack of evidence in this regard [10-12]. Finally, the sensory innervation of WAT is histologically known for decades, but its function was revealed more recently; it seems that sensory innervation is essential in the regulation of sympathetic innervation by forming feedback loops [13].

In addition to adipocytes, WAT contains macrophages, leukocytes, fibroblasts, cell progenitors, and endothelial cells. The presence of fibroblasts, macrophages, and other leukocytes, along with adipocytes, realizes the great variety of proteins that are secreted by WAT under varying conditions. White adipose tissue is distributed over the entire body and has different compartments that vary in terms of cell size $[14,15]$, metabolic activity, and its potential role in insulin resistance and other vascular complications associated with obesity $[16,17]$.

In humans, two main depots of white adipose tissue are differentiated: subcutaneous depot corresponding to the adipose tissue located under the skin ( $80 \%$ of total fat) and the visceral depot. There are two types of visceral adipose tissue: mesenteric and omental [18]. The first one is wrapped around the intestine; the second one extends from the lower part of the stomach, covering the abdomen, and is normally used in the study of visceral fat. In obesity, ectopic lipid deposition occurs mainly in liver, muscle, and heart. Over years, it is well known that the subcutaneous and visceral adipose tissues have different molecular, cellular, and anatomical features [19, 20]; for example, the irrigation of both tissues is different [21], and the mRNA levels of leptin in the subcutaneous adipose tissue are increased as compared to the visceral adipose tissue [19]. These tissues are also different in terms of the capacity for fatty acid mobilization [22]. Thus, omental fat is more sensitive to the lipolytic effects of catecholamines and less sensitive to the antilipolytic effects of insulin; therefore, this tissue has a greater capacity for fatty acid mobilization and release into the portal circulation than the subcutaneous reservoir $[21,23]$.

2.2. BAT. The brown adipose tissue consists of brown adipocytes and remaining stroma vascular fraction (SVF) including adipocyte cell progenitors [8]. Thus, the brown adipocyte has a polygonal shape with an oval and centered nucleus on a large cytoplasm that contains multiple and small lipid droplets. It has a large number of mitochondria and an underdeveloped endoplasmic reticulum. In addition, BAT is highly vascularized and innervated [8]. While the sympathetic innervation of BAT is evident [24-26], the parasympathetic innervation is controversial and it seems to be confined to the mediastinal [27] and pericardial BAT [28]. In addition to sympathetic and parasympathetic innervation, it has been described that BAT has sensory innervation; however, the information about the role of this innervation is scarce [29-31].

Originally, it was thought that the BAT was only present in humans during the neonatal period. However, more recently, data have shown that adults retain some metabolically active depots of BAT that respond to cold and sympathetic activation of the nervous system [32]. Such depots are UCP1 positive and are detected by positron emission tomography (PET) [32]. Currently, in humans, brown adipose tissue has been detected in cervical, supraclavicular, paravertebral, mediastinal, para-aortic, and adrenal regions [32]. In addition, small groups of brown adipocytes inside of the skeletal muscle were also found in mice [7]. On the other hand, recent data have shown that brown adipocytes found inside white adipose tissue depots are not derived from myf5 lineage, such as the classic brown adipocytes of the interscapular tissue of rodents, and are known as "beige" or "brite cells" [33-35]. These cells are positive for UCP-1, with high respiratory capacity, with characteristics of both white and brown adipose tissues and being highly responsive to the polypeptidic hormone irisin [36]. In this sense, it has recently been shown that the exercise-induced irisin secreted by skeletal muscle induces the "browning" of subcutaneous white adipose tissue. However, this protein has little effect on the classic brown adipocytes isolated from the interscapular reservoir [37]. These results suggest that the responsiveness to irisin might be a selective feature of beige cells localized inside of subcutaneous white adipose tissue and improve metabolic and vascular complications associated with obesity [37-40]. Besides its implication in thermogenesis, recent studies have shown that brown adipose tissue could be involved in the reduction of triglyceride and glucose levels and also serve as a source of adipokines playing a different role in the inflammatory response as compared to WAT [41-43].

2.3. PVAT. Perivascular adipose tissue is located around the coronary artery (or epicardial adipose tissue), the aorta (periaortic adipose tissue), and other systemic vessels as well as the microcirculatory bed of the mesenteric, muscle, kidney, and adipose tissue, with the exception of the brain circulation [44]. It joins the adventitious layer without any laminar structure or organized barrier. Depending on the vascular bed, PVAT may have more or less characteristics of white or brown adipose tissue. Thus, it has been described that PVAT from the abdominal artery would be essentially white adipose tissue; the PVAT in human coronary arteries would have an intermediate phenotype between brown and white adipose tissues and the PVAT from thoracic aortic artery would be very similar to the brown adipose tissue 
$[45,46]$. Functionally, similar to BAT, it has been described that lipid clearance and maintenance of intravascular temperature were impaired in response to cold exposure in mice lacking PVAT [47]. Vascularization and innervation of the PVAT considerably vary with location and this could explain the different functional features of PVAT. Indeed, it has been shown that PVAT of human saphenous vein also receives direct sympathetic innervation [48].

\section{Adipose Tissues as Endocrine Organs}

3.1. WAT. The white adipose tissue is not only an energy reservoir but also a secretory organ of certain molecules that have endocrine, paracrine, and autocrine actions [49]. Some of these molecules secreted by adipocytes are involved in the regulation of body weight (leptin, adiponectin), in the local inflammation generated in obesity (TNF- $\alpha$, IL-6, and IL-1 $\beta$ ), in vascular function (Ang II and PAI-1), or in breeding (estrogens, among others).

Leptin is a hormone mainly secreted by the adipocytes that plays an important role in the regulation of body weight through its central effects on appetite and peripheral effects on the regulation of energy expenditure [50]. The vast majority of obese patients present high concentrations of leptin that are increased depending on the degree of adiposity and hyperinsulinemia, which is referred nowadays as leptin resistance [51]. This hyperleptinemia has been involved in the insulin resistance showed by obese subjects through alterations in insulin receptor phosphorylation [52]. Another hormone secreted by adipocytes that participates controlling food intake is adiponectin. In several studies, hypoadiponectinemia has been observed in patients with obesity, diabetes mellitus, and coronary artery disease [53, 54]. In addition to its antidiabetogenic and antiatherogenic effect, it also has an inverse relationship with other risk factors such as blood pressure, total cholesterol, and low density lipoproteins (LDL) $[55,56]$. Cross-sectional population studies show that low adiponectin concentrations or high leptin levels are related to an increase in the metabolic and cardiovascular risk [57-59].

Different cell types including the adipocytes secrete several proinflammatory cytokines. They have paracrine or autocrine actions and participate in the local inflammatory response that occurs in the adipocytes of obese patients. It has been described that the levels of TNF- $\alpha$ in the adipocyte are positively correlated with the size of the adipose depots [60]. In addition, the levels of mRNA of TNF- $\alpha$ are increased in adipose tissue of several murine models of obesity and diabetes and obese patients, linking such increase with the development of insulin resistance [61, 62]. On the one hand, TNF- $\alpha$ activates lipolysis and inhibits the expression of LPL and GLUT-4 as a mechanism addressed to reduce the excessive size of fat depots. However, high levels of TNF$\alpha$ in adipose tissue could account for any of the metabolic alterations associated with obesity such as insulin resistance. Thus, TNF- $\alpha$ increases free fatty acid levels reducing insulin sensitivity, and, in the liver, it has an inhibitory effect on insulin action increasing the hepatic glucose production [63]. Thus, the neutralization of TNF- $\alpha$ using monoclonal antibodies reduces the glucose levels in the murine diabetic KKAy model [64] and improves the glycemic control in insulin resistant subjects [65]. Similarly, treatment with antiTNF- $\alpha$ antibodies for six weeks reduced the fasting hyperglycemia and glucose intolerance and improved insulin sensitivity in visceral white adipose tissue, mainly in gonadal depot from 52-week-old BATIRKO mice, which shows an increased adiposity associated with a severe brown fat lipoatrophy [66]. In this mouse model, treatment with anti-TNF- $\alpha$ antibodies reduced activation of NF- $\kappa \mathrm{B}$ in both adipose tissues and the expression of proteins controlled by this transcription factor both in the gonadal white adipose tissue and brown adipose tissue and in the aorta [66]. In addition, vascular insulin resistance and dysfunction were reversed by the treatment with anti-TNF- $\alpha$ antibodies [66]. Angiotensin and plasminogen activator inhibitor 1 (PAI-1) are also molecules secreted by adipocytes whose gene expression is increased in obesity $[67,68]$, showing a deleterious effect on vascular function. Moreover, another component of the renin-angiotensin system, also present in adipocytes, is angiotensin II, which has a positive effect on the differentiation of adipose tissue and regulates adiposity owing to their lipogenic actions [69]. In relation to PAI-1 secretion by adipose tissue, an increased production in visceral fat has been observed as compared to subcutaneous fat. In fact, PAI-1 levels were increased in the central obesity related to its associated vascular alterations [68].

3.2. BAT. Brown adipose tissue is also an endocrine organ like WAT and secretes different cytokines, hormones, and other factors such as TNF- $\alpha$, adiponectin, and leptin. However, there are a large number of molecules that are also secreted by BAT. Many of these, including fibroblast growth factor type 21 (FGF21), are required to cold adaptation and adrenergic stimulation [70-72]. In addition, FGF21 can also act directly on brown adipose tissue, regardless of the adrenergic control, opening new pathways to explore mechanisms that control body fat [73]. Other proteins secreted by BAT such as adipsin, FGF2, IGF-1, prostaglandins, and adenosine have autocrine actions.

In addition, BAT secretes other proteins such as IL6 and neurotrophic factors including BDNF (brain-derived neurotrophic factor) and nerve growth factor (NGF), which could have different roles in BAT as compared to WAT [74, 75]. NGF secretion occurs mainly by brown preadipocyte proliferation, which promotes sympathetic innervation triggering greater norepinephrine stimulation. Other paracrine factors, besides the neurotrophic, synthesized by BAT are vascular endothelial growth factor (VEGF), angiotensinogen, and nitric oxide. The expression of VEGF is increased during the proliferation and differentiation of brown adipocytes, in order to maintain a high level of vascularization. Both noradrenaline and cold exposure induce an increased expression of VEGF in BAT [76]. On the other hand, nitric oxide (NO) produced mainly by endothelial nitric oxide synthase (eNOS) might be responsible for the physiological regulation of blood flow as well as for thermogenesis in BAT, and the authors also suggest that eNOS activity and expression may be controlled by sympathetic nerve activity [77]. 
Unlike the white adipose tissue that is quickly infiltrated by inflammatory cells in response to high-fat diet-induced obesity, brown adipose tissue does not appear to accumulate such infiltrate of macrophages [78]. This may be due to the larger number of mitochondria of BAT, which allows fatty acid metabolism through $\beta$-oxidation. However, in WAT, the ability to metabolize lipids would be exceeded, having lipotoxic effects, triggering the inflammatory response and facilitating the infiltration of macrophages and immune cells [79]. In this sense, another group has recently demonstrated that the macrophages from brown adipose tissue do not have the same expression profile of cytokines and chemokines as those from white adipose tissue [79].

3.3. PVAT. The PVAT like other adipose depots releases adipocytokines, such as adiponectin, leptin, IL-6, and TNF$\alpha$. PVAT establishes a communication with the other layers of the vessel wall through the vasa vasorum, being different from the actions of the other adipose tissues. Moreover, PVAT activity has direct paracrine action in vascular smooth muscle cells from media layer and endothelial cells from intima layer [80]. Thus, the main endocrine actions of PVAT on vascular cells are the regulation of vessel tone in physiological conditions and vessel remodeling in pathophysiological conditions [80]. In this regard, inflammatory cells in PVAT might be implicated in the recruitment and/or proliferation of adventitial myofibroblasts and finally contribute to vascular remodeling. Therefore, in response to vascular damage or high-fat diet, PVAT produces proinflammatory adipocytokines upregulation and adiponectin downregulation [81, 82]. In addition, the prochemotactic activity of PVAT due to the accumulation of inflammatory cells between the PVAT and the adventitia layer of human atherosclerotic aortas has been described [82]. In contrast to other adipose depots, PVAT cells secrete greater amounts of angiogenic factors. So, hepatocyte growth factor (HGF) is mainly secreted by PVAT cells and induces endothelial cell growth and cytokine release from smooth muscle cells [83].

\section{Role of Adipose Tissues in Obesity-Induced Inflammation and Its Associated Vascular Complications}

4.1. WAT. There are numerous differences between visceral and subcutaneous adipose tissues related to adipokine secretion [84]. In this sense, peripheral obesity is characterized by an accumulation of subcutaneous adipose tissue and is more frequent in women. This type of obesity is not associated with an increased risk of related pathologies [85]. However, central or abdominal obesity is more common in men and consists of an accumulation of visceral adipose tissue. This type of obesity has been associated, through epidemiological studies, with a higher risk of diseases such as insulin resistance, type 2 diabetes, and hypertension, greatly increasing cardiovascular risk [86].

Under obesity, diet excess and obesity itself produce an accumulation of lipids in adipocytes, triggering cellular stress and the activation of JNK and NF- $\kappa \mathrm{B}$ pathways
$[87,88]$. These inflammatory signaling pathways regulate the phosphorylation of proteins and different transcriptional events that lead to an increase in the production of proinflammatory molecules, including TNF- $\alpha$, IL-6, leptin and resistin, chemokines such as monocyte chemoattractant protein 1 (MCP-1), and other proatherogenic mediators, such as PAI-1. Endothelial adhesion molecules (e.g., ICAM-1 and VCAM-1) and chemoattractant molecules (e.g., CCX) bind to integrins and chemokines receptors (CCR), respectively, and they favor the recruitment of monocytes and other inflammatory cells to the adipose tissue. Internalized monocytes differentiate to macrophages and amplify the inflammatory response producing many of the same inflammatory cytokines and chemokines described above [89] (Figure 1). Some recent articles have also suggested that $\mathrm{T}$ cells could play an important role in both the production of proinflammatory cytokines and the recruitment of macrophages to the adipose tissue in obese patients [90]. The lymphocytes infiltration precedes the population of monocytes in response to high-fat diet and could provide proinflammatory mediators, which promote the recruitment and activation of macrophages (Figure 1). Cytotoxic T lymphocytes CD8+ are highly enriched in the adipose tissue of mice subjected to high-fat diet, which is consistent with the significant increase of CD8+ cells in obese patients [90]. Thus, mice deficient in CD8 were partially resistant to develop high-fat dietinduced obesity, while the transfer of CD8+ cells aggravated inflammation of adipose tissue [90].

Besides fat and inflammatory cells, other cell types could participate in the inflammatory response. Thus, the adipose tissue is vascularized with multiple capillaries in contact with each adipocyte [91]. In this sense, for fat expansion, microcirculation could play a key role in adipose tissue inflammation. Thus, leukocytes will not adhere to a normal nonstick endothelium, while endothelium expresses adhesion molecules and binds leukocytes upon high-fat diet administration [92]. Endothelial cells from adipose tissue could increase adhesion proteins, such as ICAM-1, VCAM1, E-selectin, and P-selectin in response to an increased adiposity and thus promote the adhesion of inflammatory $\mathrm{T}$ cells and monocytes [93].

Increased adiposity activates inflammatory response not only in adipocytes but also in the liver through the portal vein [94] (Figure 1). This suggests that lipid accumulation in the liver or steatosis may induce a subacute inflammatory response in this organ, which is similar to the local inflammation observed in adipose tissue that follows lipid accumulation in the adipocyte [94-96]. Proinflammatory molecules produced in abdominal fat through the portal circulation could be responsible for the onset of liver inflammation. In addition, in the fatty hepatocyte, activation of NF- $\kappa \mathrm{B}$ and an increase in the expression of cytokines occur, including TNF- $\alpha$, IL-6, and IL-1 $\beta$ [94]. Proinflammatory cytokines are involved in the development of insulin resistance and activate the resident hepatic macrophages (Kupffer cells). In obesity, increased adiposity does not increase the number of Kupffer cells but its activation occurs [94]. In the liver, there are different cells types involved in local inflammation and insulin resistance such as immune and endothelial cells 


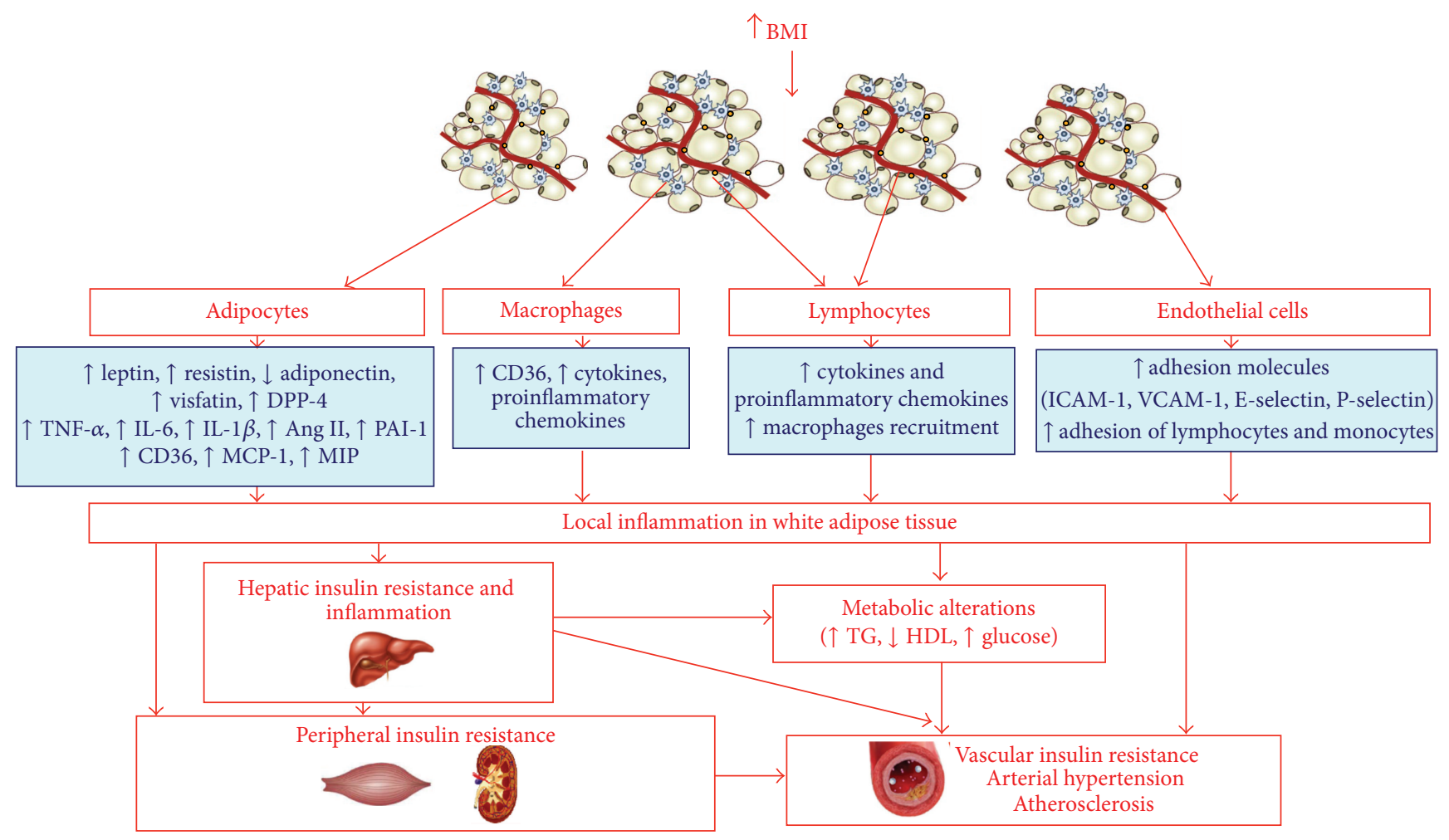

FIGURE 1: Contribution of white adipose tissue to obesity and its associated metabolic and vascular complications. Obesity is a proinflammatory state of low grade. Adipocytes, infiltrated macrophages, and lymphocytes in addition to endothelial cells from capillaries close to adipocytes contribute to local inflammation in WAT. In obesity an increase of lipid accumulation takes place in adipocytes, triggering cellular stress and the activation of JNK and NF- $\kappa \mathrm{B}$ pathways leading to local inflammation in the adipocyte. The inflammation can go through the portal vein to the liver and finally to other peripheral tissues like vascular tissues where it can produce atherosclerosis, hypertension, and vascular insulin resistance.

[95]. Therefore, the proinflammatory and proatherogenic mediators, which are produced by the adipose tissue and liver and associated with immune cells, generate a systemic inflammation that produces insulin resistance in skeletal muscle and other peripheral tissues. In the vascular tissue, insulin resistance could help to initiate the atherogenic process [96] (Figure 1).

In this sense, it has been described that novel and relevant adipokines as visfatin and dipeptidyl peptidase 4 (DPP-4) are produced by white adipose tissue that might have great impact on cardiovascular complications associated with obesity. So, visfatin had strongly been related to proinflammatory factors in severe obesity [97], a novel marker of hypertension in advanced age patients [98] and a predictor of inflammation and endothelial injury in several metabolic diseases [99]. In this regard, it has been demonstrated that visfatin/Nampt might exert direct deleterious actions on the cardiovascular system, including cell proliferation, monocyte/macrophage activation and recruitment, vascular inflammation, and remodeling, all of which leading to the development of atherosclerotic lesions [99]. In addition, DPP4 is also positively correlated with adiposity [100] and insulin resistance in diabetic patients [101, 102]. DPP-4 is a ubiquitous enzyme that regulates incretins and consequently is related to the pathophysiology of Type 2 Diabetes Mellitus.
DPP4 is mainly secreted by adipocytes and endothelial cells and acts as a regulatory protease for cytokines, chemokines, and neuropeptides involved in inflammation, immunity, and vascular function [103].

4.2. BAT. In mice, the activation of brown adipose tissue reduces adiposity and protects from the high-fat diet-induced obesity $[104,105]$. Thus, the loss of BAT mass [5], such as the severe brown lipoatrophy induced by the insulin receptor deletion in that tissue $[66,105]$, or the loss of UCP-1 [106] confers susceptibility to obesity in mice. In recent years, it has been described that the amount of BAT was inversely correlated with the body mass index in humans, especially in aged people [32]. In addition, it has recently been shown that BAT could protect against multiple diseases associated with ageing [8]. Thus, individuals with smaller depots of BAT are more susceptible to accumulate WAT and to increase body weight showing an increased risk of developing metabolic and vascular alterations $[96,107]$.

Besides thermogenesis, recent studies have demonstrated that BAT could have a leading role in lipid and carbohydrate metabolism (Figure 2). Firstly, brown adipose tissue may be involved in the reduction of elevated triglyceride concentrations and therefore in the reduction of obesity in humans [41, 108]. Thus, triglyceride-rich lipoproteins (TRLs) carry lipids 


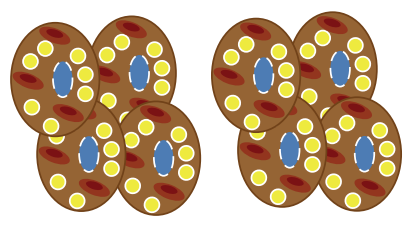

BAT

$(\downarrow$ mass or activity)

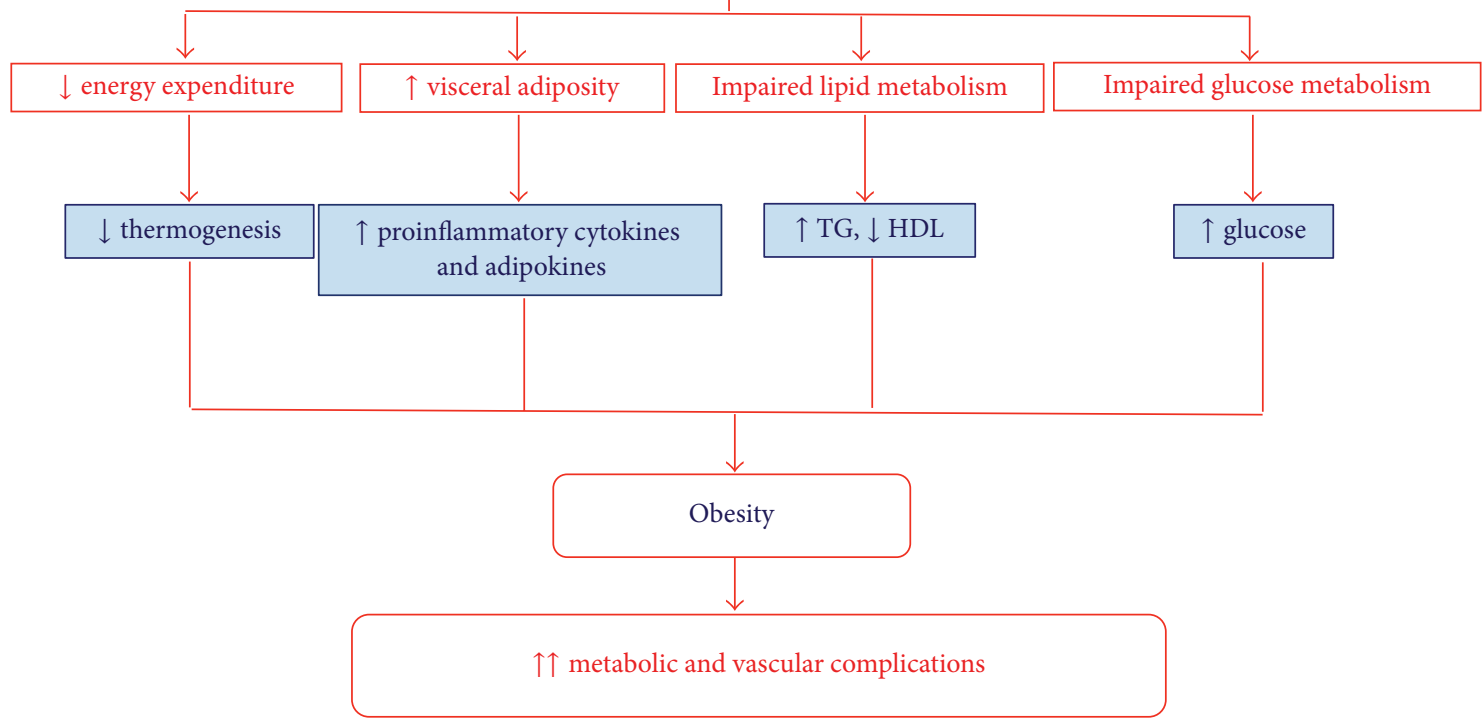

FIGURE 2: Contribution of brown adipose tissue to obesity and its associated metabolic and vascular complications. One of the possible causes that induce the development of obesity could be a decrease in the amount and activity of the brown adipose tissue. In this situation, there would be an alteration of functions that perform brown adipose tissue on lipid metabolism and carbohydrate as well as the expression profile of cytokines and adipokines, favoring obesity and the related metabolic and vascular complications.

within circulation, where a portion of fatty acids can be liberated by LPL [109]. Other peripheral organs such as white adipose tissue and skeletal muscle capture fatty acids, while the remnant cholesterol-rich particles are removed by the liver [109]. In addition, high levels of triglycerides and cholesterolrich remnant particles, as in diabetic dyslipidemia, represent risk factors to develop cardiovascular diseases [110, 111]. It has been described that the increased activity of BAT by short exposures to cold could control the metabolism of the TRLs in mice, by regulating the removal of these lipoproteins and the excess of circulating lipids [41] and thus decreasing the levels of triglycerides and slightly increasing HDL levels (Figure 2). Thus, fatty acids are efficiently introduced into the brown adipose tissue due to a metabolic program that pushes TRLs to a highly efficient uptake of fatty acids. This process associated with an increase in the expression of VEGF [112] leads to an increase of lipoprotein permeability, allowing triglycerides to come out of the capillaries. The BAT switched on by norepinephrine not only activates the fatty acid release from triglycerides and a greater production of VEGF but also increases the expression of LPL $[41,113]$. Therefore, LPL degrades triglycerides and allows that fatty acids may be available through plasma membrane transporters as CD36. In addition, it has been shown in humans that activation of BAT by cold exposure increases its oxidative metabolism, reducing triglyceride content and contributing decisively to energy expenditure [114]. Therefore, the activation of BAT would be able to correct the hyperlipidemia, improving the deleterious effects of obesity and dyslipidemia such as insulin resistance or the atherogenic process. So, this year, it has been described that BAT activation reduces plasma triglyceride and cholesterol levels and attenuates diet-induced atherosclerosis development in an experimental model [42]. Initial studies suggest that BAT activation in humans may also reduce triglyceride and cholesterol levels, but potential antiatherogenic effects should be assessed in future studies $[42,114]$.

On the other hand, it has also been described that BAT could regulate carbohydrate metabolism [41] (Figure 2). The mitochondria from BAT use pyruvate for combustion whenever UCP-1 is activated by fatty acids [115]. In addition, glucose transporters GLUT-1 and GLUT-4, may be involved in the glucose uptake by BAT since the activity and expression of both transporters are augmented by both cold exposure and norepinephrine [41, 116-118].

4.3. PVAT. Perivascular adipose tissue that extends from adventitious layer is a key modulator of the vascular function in both thin animal models and subjects. However, in pathological conditions especially obesity-related cardiovascular diseases, the beneficial effects of PVAT on vascular functions are impaired (PVAT dysfunction) and transformed into 


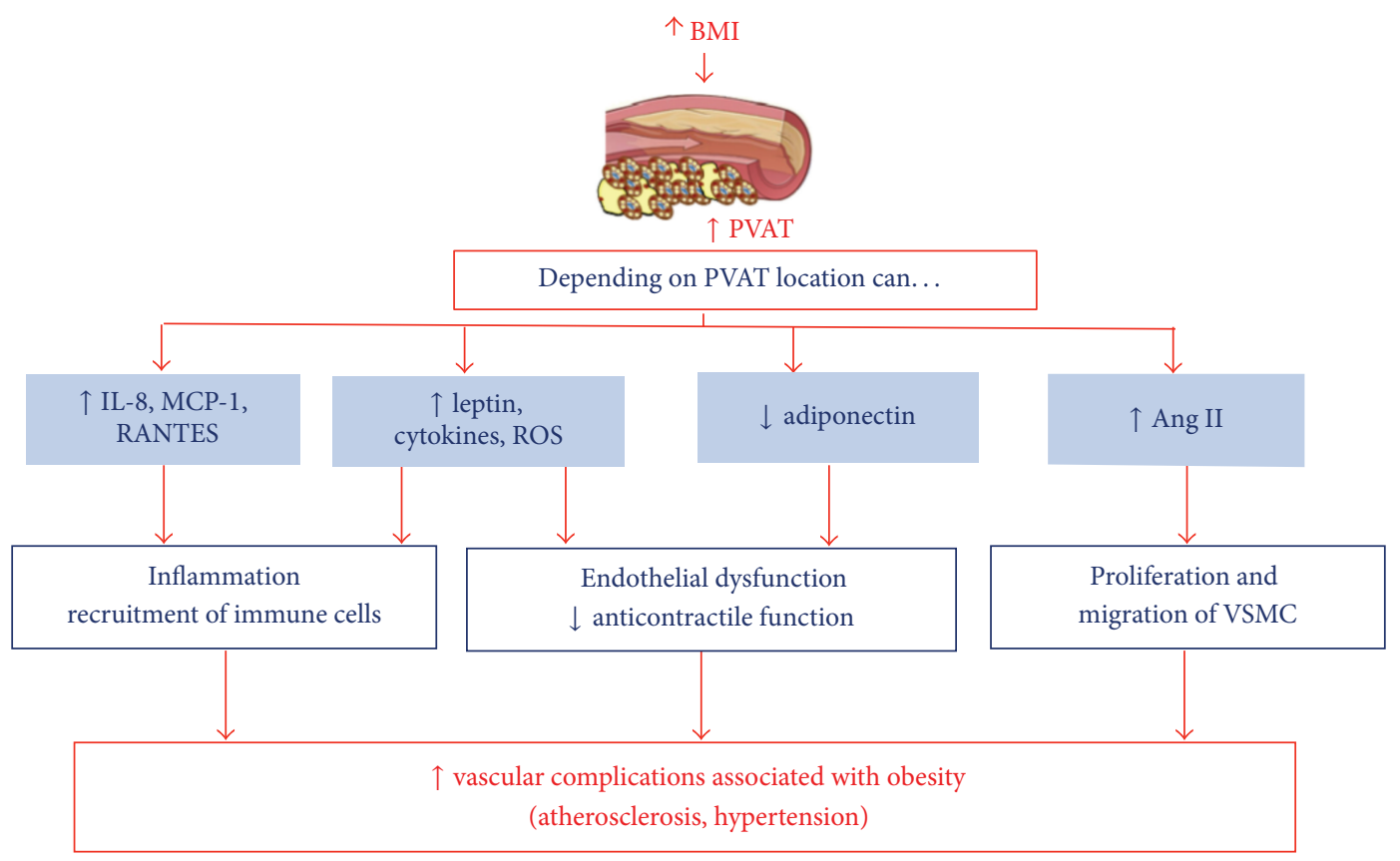

FIGURE 3: Contribution of perivascular adipose tissue to obesity and its associated metabolic and vascular complications. Perivascular adipose tissue depending on its location interacts with the endothelium, vascular smooth muscle cells, and immune cells. In the same way, there are certain mediators that would be involved in the vascular disorders associated with obesity, such as hypertension and atherogenesis.

detrimental roles [119]. So, the perivascular tissue increases its size, creating an environment of hypoxia that could decrease the production of adiponectin, which has protective effects against atherogenesis and other vascular complications [46] (Figure 3). Like other adipose tissue depots, PVAT also secretes many biologically active substances that can act in both autocrine and paracrine fashion. PVAT has also a proven role in vascular inflammation [119-121]. On the other hand, it has been described that diet-induced weight loss reverses obesity-induced PVAT dysfunction through a mechanism involving reduced inflammation and increased nitric oxide synthase activity within PVAT [122].

In addition, in obesity and metabolic syndrome, PVAT loses its vasoregulatory capability due to a decreased release of vasodilator adipokines and a simultaneous increase in vasoconstrictor factors release [123]. Thus, the perivascular adipose tissue has anticontractile properties that are lost in obesity [44, 124] (Figure 3). It has also been described that an increased PVAT could be positively correlated with the amount of intra-abdominal adipose tissue [125]. Therefore, in obesity and atherosclerosis, PVAT, in addition to increase its size, can be infiltrated by immune cells, such as macrophages and $\mathrm{T}$ lymphocytes $[78,126]$. The accumulation of $\mathrm{T}$ lymphocytes could favor the expansion of adipose tissue due to adipogenesis stimulation by increased 15d-PGJ2 production and PPAR- $\gamma$ activation [127]. However, macrophages do not affect PVAT expansion but produce cytokines that alter its adipokine secretion [82]. Thus, lower adiponectin levels [124] and elevated leptin levels [81, 127], proinflammatory cytokines and chemokines [128-130], and reactive oxygen species (ROS) [44, 131] and esterified fatty acids [104] have been described in PVAT from both obese patients and animal models of obesity (Figure 3).

However, it has been described that the inflammatory properties of the epicardial adipose tissue are independent of obesity [132]. In this regard, recent studies in mice have also shown that the PVAT surrounding the thoracic aorta artery is very similar to BAT in terms of morphology and gene expression profile [78]. In addition, perivascular adipose tissue in the thoracic aorta together with BAT is more resistant to inflammation induced by high-fat diet [78] (Figure 3). Moreover, the PVAT that has thermogenic properties similar to BAT in rodents and beige fat in humans together with the triglyceride clearance might inhibit the development of atherosclerosis [47]. It would be interesting to check if the perivascular adipose tissue in obese patients with and without cardiovascular disease has a similar morphology and gene expression profile to BAT in the studied murine models. Thus, the activation of BAT phenotype in PVAT could be beneficial in order to prevent vascular diseases associated with obesity, such as hypertension and atherogenesis.

\section{New Perspectives in the Treatment of Obesity}

An early indication for the treatment of obesity along with caloric restriction is physical exercise in dosed way appropriate to the physical condition of each patient. There are considerable evidences that caloric restriction increases the life expectancy [133] and reduces the risk of developing diabetes, cardiovascular disease, degenerative disorders, and some types of cancer [133, 134]. In addition to caloric 
restriction, there are evidences showing that an energy balance maintained for several months, which includes an increase in energy expenditure, tends to be effective in lowering adiposity. This reduction occurs mainly in visceral fat, which possesses the highest lipolytic activity as compared to adipose tissue from other regions [135]. In addition, people with a good physical condition have greater lipolysis than those inactive [136]. Another aspect that enhances the physical exercise in obese patients is the lipid profile. First, it raises HDL levels and therefore lowers the LDL/HDL ratio and cardiovascular risk [137]. In addition, exercise increases the size of the LDL and HDL particles leading to a less atherogenic lipid profile than those small LDL and HDL particles, typical of obese patients [138]. Moreover, a regular physical exercise also decreases triglyceride levels in those individuals with initially high values, through an improvement in insulin sensitivity $[138,139]$. Physical exercise also produces an increase in oxidative potential and thus promotes the metabolism of more lipids and carbohydrates in the aerobic way, producing very desirable peripheral adaptations. Therefore, the physical exercise normalizes metabolic profile and allows the reduction of morbidity and mortality due to these causes [140,141].

In addition to the role played by peripheral tissues, energy homeostasis is strongly controlled by the Central Nervous System (CNS). Several areas of the brain that constitute cognitive and autonomic brain systems form networks involved in the control of food intake and thermogenesis, also contributing to energy homeostasis [142]. These networks include the dopamine mesolimbic circuit, the opioid, endocannabinoid, and melanocortin systems. The activity of all these pathways is modulated by peripheral factors such as hormones derived from adipose tissue and the gut, which access the brain via the circulation and neuronal signaling pathways to inform the central nervous system about energy balance and nutritional status. The balance between food intake and energy expenditure is achieved via a highly coordinated communication between the executive, reward, and autonomic circuits in the brain and circulating homeostatic signals [143].

Changes in energy stores induced by food deprivation, overfeeding, or excess physical activity lead to adaptations in the controls of energy intake and expenditure that oppose them. These changes are signaled to reward and autonomic SNS circuits by peripheral hormones, such as leptin and ghrelin. Leptin, whose production varies with the size of the adipocytes in WAT [144], can initiate its central actions via the hypothalamus and VTA (ventral tegmental area) [145, 146]. Similarly ghrelin, also influenced by the nutritional status, can also act on the hypothalamus, VTA, and the DVC (dorsal vagal complex) [147, 148]. These regulatory processes seem particularly effective preventing the reduction in energy/fat reserves which seem resolutely "defended." Such a reduction leads to regulatory responses that promote energy intake $[149,150]$ and reduce energy expenditure [151], which unpins the difficulty in an individual's ability to combat obesity [152]. The antiobesity agents whose mechanism is based on the control of CNS present a moderate efficacy in the long term [153]; moreover, these agents produce many central compensation and side effects such as headache, dizziness, fatigue, nausea, dry mouth, cough, constipation, paresthesias, taste alterations, insomnia, elevation in heart rate and memory, or cognitive changes $[154,155]$.

In recent years, several antiobesity drugs designed to limit energy intake have been withdrawn from the market due to serious adverse effects [156]. Nowadays, only two drugs are approved specifically for weight loss by the US FDA: the lipase inhibitor (Orlistat) that is also approved by the European Medicines Agency but has a limited long-term effectiveness [157] and the recently approved novel selective agonist of the serotonin 2C receptor (Lorcaserin) [158]. Thus, more efforts are needed to develop new antiobesity agents. In this regard, strategies designed to increase lipid mobilization and oxidation could be very useful in the treatment of obesity and associated diseases. In this sense, there are some antidiabetic medications in the market that promote weight loss and improve cardiovascular outcomes [159]. So, inhibition of DPP4 enzyme activity increases endogenous intact glucagonlike peptide-1 (GLP-1), thereby stimulating insulin secretion that subsequently lowers blood glucose. Therefore, multiple DPP4 inhibitors have been developed for treating type 2 diabetes [160]. Although various gliptins are known to be neutral on body weight in type 2 diabetic patients, the effect on body fat mass has not been fully elucidated in humans and animals yet [161-163]. However, recently it has been described that fat loss by the DPP4 inhibitor evogliptin, in contrast to exenatide, might likely be mediated by increased energy expenditure and alteration in white adipose tissue metabolism from obese mice [100].

Other pharmacologic treatments for type 2 diabetes are PPAR $\gamma$ agonists as thiazolidinediones (TZDs) because $\operatorname{PPAR} \gamma$ regulates multiple pathways involved in the pathogenesis of diabetes, obesity, and atherosclerosis. Previous studies have proposed that these antidiabetic agents might also present diverse pleiotropic effects, such as improvement of the lipid profile [164], endothelial dysfunction [165], and decreased inflammation [166]. In order to avoid side effects associated with TZDs, new drugs have been developed targeting different PPAR isotypes (dual agonists) and more selective PPAR $\gamma$ partial agonists $[167,168]$. This year, a new thiazolidinedione, CQ-1777, partial PPAR $\gamma$ agonist improved obesity-associated insulin resistance and dyslipidemia with atheroprotective effects in atherosclerosis mice model. Moreover, CQ-1777 did not affect body weight, food consumption, fat accumulation, or bone density [169].

In order to fight this global epidemic represented by obesity and its associated metabolic and cardiovascular complications, the pharmacological activation of the SNS does not appear to be useful due to negative side effects [170]; scientists must join efforts to advance the knowledge of brown adipose tissue and its promising therapeutic potential against obesity and related complications [169-171]. It has been described that adaptive response of brown adipose tissue to a moderate and intermittent stress through sympathetic activation could increase the proliferation and differentiation of brown adipocyte progenitors and increase mitochondrial mass and UCP-1 expression in this tissue [172]. All of those effects, along with the stimulation of BAT depots in white 
adipose tissue or skeletal muscle [173-176], could increase energy expenditure and reduce oxidative stress in visceral adiposity. However, some clinical trials performed with $\beta 3$ AR agonists have not achieved a significant response in terms of weight loss and energy balance [177-180]. Interestingly, transplantation of brown adipose tissue (0.1-0.4 g) to the visceral cavity in mice is able to prevent weight gain and improve the glucidic homeostasis in obese mice subjected to highfat diet [181]. As it has been described, activation of brown adipose tissue deposits in humans, which are composed of beige adipocytes [35], could open a new research line to determine if this type of cells may have some therapeutic potential. In recent years, it has been proposed that fat browning can be used as a therapeutic tool for metabolic disorders and cardiovascular diseases. Firstly, adaptive changes of skeletal muscle in response to exercise include adjustments in the production and secretion of myokines that induce myogenesis and fat browning together with a concomitant increase in energy expenditure [182]. Although exercise has been the most common factor for fat browning [183], there are some other factors implicated. So, browning of WAT can be achieved by several different means [173] including CNS activation modulating sympathetic output to WAT and the recruitment and activation of immune cells. Moreover, WAT browning can be reached by direct action on white adipocytes or beige precursor cells through the activation of PPAR $\alpha$ [184], PPAR $\gamma$ [185], FGF21 [186], IL6 [187], natriuretic peptides [188], beta aminoisobutyric acid (BAIBA) [189], gamma aminoisobutyric acid, or JAK inhibition [190]. Recently, two novel factors as musclin and TFAM have been proposed for fat browning [190]. Musclin is a myokine produced by muscle during exercise [191], activates PPAR $\gamma$, and, therefore, induces WAT browning having beneficial metabolic and cardiac effects [190, 191]. TFAM is a transcription factor involved in mitochondrial biogenesis and, therefore, has also been involved in WAT browning [190].

In addition to musclin, irisin, another novel adipomyokine, is involved in the browning of WAT during exercise in mice models [37]. However, the impact of irisin on white-tobrown transdifferentiation in humans has been heavily questioned $[192,193]$. In the last years, it has been proposed that irisin can exert cardioprotector effects $[194,195]$ and improves endothelial function due to the activation of the AMPKeNOS signaling pathway [40]. Finally, $\alpha$-lipoic acid promotes mitochondrial biogenesis and brown-like remodeling in cultured white subcutaneous adipocytes from overweight/obese donors [196].

\section{Conclusions}

Finally, given the capacity of brown adipose tissue in energy expenditure and the effects on carbohydrate and lipid metabolism, as well as their potential resistance to inflammation together with perivascular adipose tissue, new perspectives for the treatment of obesity could focus on the design of new drugs or different regimes or therapies that increase the amount and function of brown adipose tissue not only to combat obesity but also to prevent type 2 diabetes and other associated vascular and metabolic disorders.

\section{Competing Interests}

The authors declare that they have no competing interests.

\section{References}

[1] B. Caballero, "The global epidemic of obesity: an overview," Epidemiologic Reviews, vol. 29, no. 1, pp. 1-5, 2007.

[2] G. Cascio, G. Schiera, and I. Di Liegro, "Dietary fatty acids in metabolic syndrome, diabetes and cardiovascular diseases," Current Diabetes Reviews, vol. 8, no. 1, pp. 2-17, 2012.

[3] P. Mathieu, I. Lemieux, and J.-P. Després, "Obesity, inflammation, and cardiovascular risk," Clinical Pharmacology and Therapeutics, vol. 87, no. 4, pp. 407-416, 2010.

[4] W. Aldhahi and O. Hamdy, "Adipokines, inflammation, and the endothelium in diabetes," Current Diabetes Reports, vol. 3, no. 4, pp. 293-298, 2003.

[5] B. B. Lowell, V. S-Susulic, A. Hamann et al., "Development of obesity in transgenic mice after genetic ablation of brown adipose tissue," Nature, vol. 366, no. 6457, pp. 740-742, 1993.

[6] X. Yang, S. Enerbäck, and U. Smith, "Reduced expression of FOXC2 and brown adipogenic genes in human subjects with insulin resistance," Obesity Research, vol. 11, no. 10, pp. 1182-1191, 2003.

[7] K. Almind, M. Manieri, W. I. Sivitz, S. Cinti, and C. R. Kahn, "Ectopic brown adipose tissue in muscle provides a mechanism for differences in risk of metabolic syndrome in mice," Proceedings of the National Academy of Sciences of the United States of America, vol. 104, no. 7, pp. 2366-2371, 2007.

[8] M. P. Mattson, "Perspective: does brown fat protect against diseases of aging?" Ageing Research Reviews, vol. 9, no. 1, pp. 6976, 2010.

[9] M. T. Foster and T. J. Bartness, "Sympathetic but not sensory denervation stimulates white adipocyte proliferation," American Journal of Physiology-Regulatory, Integrative and Comparative Physiology, vol. 291, no. 6, pp. R1630-R1637, 2006.

[10] F. Kreier, E. Fliers, P. J. Voshol et al., "Selective parasympathetic innervation of subcutaneous and intra-abdominal fatfunctional implications," Journal of Clinical Investigation, vol. 110, no. 9, pp. 1243-1250, 2002.

[11] A. Giordano, C. K. Song, R. R. Bowers et al., "No sympathy for the claim of parasympathetic innervation of white adipose tissue," American Journal of Physiology, vol. 293, pp. R550-R552, 2007.

[12] H. R. Berthoud, E. A. Fox, and W. L. Neuhuber, "Controversial white adipose tissue innervation by the vagus nerve: seeing is believing," American Journal of Physiology, vol. 293, pp. R553R554, 2007.

[13] T. J. Bartness, Y. Liu, Y. B. Shrestha, and V. Ryu, "Neural innervation of white adipose tissue and the control of lipolysis," Frontiers in Neuroendocrinology, vol. 35, no. 4, pp. 473-493, 2014.

[14] P. R. Johnson, L. M. Zucker, J. A. Cruce, and J. Hirsch, "Cellularity of adipose depots in the genetically obese Zucker rat," Journal of Lipid Research, vol. 12, no. 6, pp. 706-714, 1971.

[15] M. Krotkiewski, P. Björntorp, L. Sjöström, and U. Smith, "Impact of obesity on metabolism in men and women. Importance of regional adipose tissue distribution," Journal of Clinical Investigation, vol. 72, no. 3, pp. 1150-1162, 1983.

[16] P. J. Coon, E. M. Rogus, D. Drinkwater, D. C. Muller, and A. P. Goldberg, "Role of body fat distribution in the decline in 
insulin sensitivity and glucose tolerance with age," Journal of Clinical Endocrinology and Metabolism, vol. 75, no. 4, pp. 11251132, 1992.

[17] A. Gastaldelli, Y. Miyazaki, M. Pettiti et al., "Metabolic effects of visceral fat accumulation in type 2 diabetes," Journal of Clinical Endocrinology and Metabolism, vol. 87, no. 11, pp. 5098-5103, 2002.

[18] P. Mårin, B. Andersson, M. Ottosson et al., "The morphology and metabolism of intraabdominal adipose tissue in men," Metabolism, vol. 41, no. 11, pp. 1242-1248, 1992.

[19] C. T. Montague, J. B. Prins, L. Sanders, J. E. Digby, and S. O'Rahilly, "Depot- and sex-specific differences in human leptin mRNA expression: implications for the control of regional fat distribution," Diabetes, vol. 46, no. 3, pp. 342-347, 1997.

[20] B. L. Wajchenberg, "Subcutaneous and visceral adipose tissue: their relation to the metabolic syndrome," Endocrine Reviews, vol. 21, no. 6, pp. 697-738, 2000.

[21] P. Björntorp, "Metabolic implications of body fat distribution," Diabetes Care, vol. 14, no. 12, pp. 1132-1143, 1991.

[22] M. Gaggini, C. Saponaro, and A. Gastaldelli, "Not all fats are created equal: adipose vs. ectopic fat, implication in cardiometabolic diseases," Hormone Molecular Biology and Clinical Investigation, vol. 22, no. 1, pp. 7-18, 2015.

[23] J. Hellmér, C. Marcus, T. Sonnenfeld, and P. Arner, "Mechanisms for differences in lipolysis between human subcutaneous and omental fat cells," Journal of Clinical Endocrinology and Metabolism, vol. 75, no. 1, pp. 15-20, 1992.

[24] J. Himms-Hagen, "Neural control of brown adipose tissue thermogenesis, hypertrophy, and atrophy," Frontiers in Neuroendocrinology, vol. 12, no. 1, pp. 38-93, 1991.

[25] T. J. Bartness, C. K. Song, and G. E. Demas, "Central nervous system innervation of brown adipose tissue," in Adipose Tissue, S. Klaus, Ed., pp. 162-200, Landes Bioscience, Georgetown, Tex, USA, 2001.

[26] T. J. Bartness and C. K. Song, "Innervation of brown adipose tissue and its role in thermogenesis," Canadian Journal of Diabetes, vol. 29, no. 4, pp. 420-428, 2005.

[27] A. Giordano, A. Frontini, M. Castellucci, and S. Cinti, "Presence and distribution of cholinergic nerves in rat mediastinal brown adipose tissue," Journal of Histochemistry and Cytochemistry, vol. 52, no. 7, pp. 923-930, 2004.

[28] M. K.-H. Schäfer, L. E. Eiden, and E. Weihe, "Cholinergic neurons and terminal fields revealed by immunohistochemistry for the vesicular acetylcholine transporter. II. The peripheral nervous system," Neuroscience, vol. 84, no. 2, pp. 361-376, 1998.

[29] D. Norman, S. Mukherjee, D. Symons, R. T. Jung, and J. D. Lever, "Neuropeptides in interscapular and perirenal brown adipose tissue in the rat: a plurality of innervation," Journal of Neurocytology, vol. 17, no. 3, pp. 305-311, 1988.

[30] A. Giordano, M. Morroni, G. Santone, G. F. Marchesi, and S. Cinti, "Tyrosine hydroxylase, neuropeptide Y, substance P, calcitonin gene-related peptide and vasoactive intestinal peptide in nerves of rat periovarian adipose tissue: an immunohistochemical and ultrastructural investigation," Journal of Neurocytology, vol. 25, no. 2, pp. 125-136, 1996.

[31] J. D. Lever, S. Mukherjee, D. Norman, D. Symons, and R. T. Jung, "Neuropeptide and noradrenaline distributions in rat interscapular brown fat and in its intact and obstructed nerves of supply," Journal of the Autonomic Nervous System, vol. 25, no. 1, pp. 15-25, 1988.
[32] A. M. Cypess, S. Lehman, G. Williams et al., "Identification and importance of brown adipose tissue in adult humans," The New England Journal of Medicine, vol. 360, no. 15, pp. 1509-1517, 2009.

[33] J. Lshibashi and P. Seale, "Beige can be slimming," Science, vol. 328, no. 5982, pp. 1113-1114, 2010.

[34] M. Cedikova, M. Kripnerová, J. Dvorakova et al., "Mitochondria in white, brown, and beige adipocytes," Stem Cells International, vol. 2016, Article ID 6067349, 11 pages, 2016.

[35] M. Giralt and F. Villarroya, "White, brown, beige/brite: different adipose cells for different functions?" Endocrinology, vol. 154, no. 9, pp. 2992-3000, 2013.

[36] J. Wu, P. Boström, L. M. Sparks et al., "Beige adipocytes are a distinct type of thermogenic fat cell in mouse and human," Cell, vol. 150, no. 2, pp. 366-376, 2012.

[37] P. Boström, J. Wu, M. P. Jedrychowski et al., "A PGC1- $\alpha$ dependent myokine that drives brown-fat-like development of white fat and thermogenesis," Nature, vol. 481, no. 7382, pp. 463-468, 2012.

[38] T.-Y. Liu, C.-X. Shi, R. Gao et al., "Irisin inhibits hepatic gluconeogenesis and increases glycogen synthesis via the PI3K/Akt pathway in type 2 diabetic mice and hepatocytes," Clinical Science, vol. 129, no. 10, pp. 839-850, 2015.

[39] J. Lu, G. Xiang, M. Liu, W. Mei, L. Xiang, and J. Dong, "Irisin protects against endothelial injury and ameliorates atherosclerosis in apolipoprotein E-Null diabetic mice," Atherosclerosis, vol. 243, no. 2, pp. 438-448, 2015.

[40] F. Han, S. Zhang, N. Hou, D. Wang, and X. Sun, "Irisin improves endothelial function in obese mice through the AMPK-eNOS pathway," American Journal of Physiology-Heart and Circulatory Physiology, vol. 309, no. 9, pp. H1501-H1508, 2016.

[41] A. Bartelt, O. T. Bruns, R. Reimer et al., "Brown adipose tissue activity controls triglyceride clearance," Nature Medicine, vol. 17, no. 2, pp. 200-205, 2011.

[42] G. Hoeke, S. Kooijman, M. R. Boon, P. C. N. Rensen, and J. F. P. Berbeé, "Role of brown fat in lipoprotein metabolism and atherosclerosis," Circulation Research, vol. 118, no. 1, pp. 173-182, 2016.

[43] D. Medrikova, T. P. Sijmonsma, K. Sowodniok et al., "Brown adipose tissue harbors a distinct sub-population of regulatory T cells," PLoS ONE, vol. 10, no. 2, article e0118534, 2015.

[44] R. I. Meijer, E. H. Serne, Y. M. Smulders, V. W. M. van Hinsbergh, J. S. Yudkin, and E. C. Eringa, "Perivascular adipose tissue and its role in type 2 diabetes and cardiovascular disease," Current Diabetes Reports, vol. 11, no. 3, pp. 211-217, 2011.

[45] B. Cannon and J. Nedergaard, "Brown adipose tissue: function and physiological significance," Physiological Reviews, vol. 84, no. 1, pp. 277-359, 2004.

[46] S. B. Police, S. E. Thatcher, R. Charnigo, A. Daugherty, and L. A. Cassis, "Obesity promotes inflammation in periaortic adipose tissue and angiotensin ii-induced abdominal aortic aneurysm formation," Arteriosclerosis, Thrombosis, and Vascular Biology, vol. 29, no. 10, pp. 1458-1464, 2009.

[47] L. Chang, L. Villacorta, R. Li et al., "Loss of perivascular adipose tissue on peroxisome proliferator-activated receptor- $\gamma$ deletion in smooth muscle cells impairs intravascular thermoregulation and enhances atherosclerosis," Circulation, vol. 126, no. 9, pp. 1067-1078, 2012.

[48] M. R. Dashwood and A. Loesch, "Does perivascular fat influence neural control of thesaphenous vein," Current Neurobiology Journal, vol. 2, pp. 71-74, 2011. 
[49] G. Frühbeck, J. Gómez-Ambrosi, F. J. Muruzábal, and M. A. Burrell, "The adipocyte: a model for integration of endocrine and metabolic signaling in energy metabolism regulation," American Journal of Physiology-Endocrinology and Metabolism, vol. 280, no. 6, pp. E827-E847, 2001.

[50] A. Martí, B. Berraondo, and J. A. Martínez, "Leptin: physiological actions," Journal of Physiology and Biochemistry, vol. 55, no. 1, pp. 43-49, 1999.

[51] M. Nakata, T. Yada, N. Soejima, and I. Maruyama, "Leptin promotes aggregation of human platelets via the long form of its receptor," Diabetes, vol. 48, no. 2, pp. 426-429, 1999.

[52] J. B. McGill, D. J. Schneider, C. L. Arfken, C. L. Lucore, and B. E. Sobel, "Factors responsible for impaired fibrinolysis in obese subjects and NIDDM patients," Diabetes, vol. 43, no. 1, pp. 104109, 1994.

[53] Y. Arita, S. Kihara, N. Ouchi et al., "Paradoxical decrease of an adipose-specific protein, adiponectin, in obesity," Biochemical and Biophysical Research Communications, vol. 257, no. 1, pp. 79-83, 1999.

[54] K. Hotta, T. Funahashi, Y. Arita et al., "Plasma concentrations of a novel, adipose-specific protein, adiponectin, in type 2 diabetic patients," Arteriosclerosis, Thrombosis, and Vascular Biology, vol. 20, no. 6, pp. 1595-1599, 2000.

[55] T. Pischon, C. J. Girman, G. S. Hotamisligil, N. Rifai, F. B. $\mathrm{Hu}$, and E. B. Rimm, "Plasma adiponectin levels and risk of myocardial infarction in men," Journal of the American Medical Association, vol. 291, no. 14, pp. 1730-1737, 2004.

[56] N. Ouchi, S. Kihara, Y. Arita et al., "Adipocyte-derived plasma protein, adiponectin, suppresses lipid accumulation and class A scavenger receptor expression in human monocyte-derived macrophages," Circulation, vol. 103, no. 8, pp. 1057-1063, 2001.

[57] M. Ryo, T. Nakamura, S. Kihara et al., "Adiponectin as a biomarker of the metabolic syndrome," Circulation Journal, vol. 68, no. 11, pp. 975-981, 2004.

[58] M. Kumada, S. Kihara, S. Sumitsuji et al., "Association of hypoadiponectinemia with coronary artery disease in men," Arteriosclerosis, Thrombosis, and Vascular Biology, vol. 23, no. 1, pp. 85-89, 2003.

[59] G. Pandey, M. S. Shihabudeen, H. P. David, E. Thirumurugan, and $\mathrm{K}$. Thirumurugan, "Association between hyperleptinemia and oxidative stress in obese diabetic subjects," Journal of Diabetes \& Metabolic Disorders, vol. 14, no. 1, article 24, 2015.

[60] G. Winkler, S. Kiss, L. Keszthelyi et al., "Expression of tumor necrosis factor (TNF)- $\alpha$ protein in the subcutaneous and visceral adipose tissue in correlation with adipocyte cell volume, serum TNF- $\alpha$, soluble serum TNF-receptor- 2 concentrations and C-peptide level," European Journal of Endocrinology, vol. 149, no. 2, pp. 129-135, 2003.

[61] G. S. Hotamisligil, P. Arner, J. F. Caro, R. L. Atkinson, and B. M. Spiegelman, "Increased adipose tissue expression of tumor necrosis factor- $\alpha$ in human obesity and insulin resistance," Journal of Clinical Investigation, vol. 95, no. 5, pp. 2409-2415, 1995.

[62] G. S. Hotamisligil, "Inflammation and metabolic disorders," Nature, vol. 444, no. 7121, pp. 860-867, 2006.

[63] G. S. Hotamisligil, A. Budavari, D. Murray, and B. M. Spiegelman, "Reduced tyrosine kinase activity of the insulin receptor in obesity-diabetes. Central role of tumor necrosis factor-alpha," The Journal of Clinical Investigation, vol. 94, no. 4, pp. 1543-1549, 1994.
[64] M. Takano, R. Nishihara, N. Sugano et al., "The effect of systemic anti-tumor necrosis factor-alpha treatment on Porphyromonas gingivalis infection in type 2 diabetic mice," Archives of Oral Biology, vol. 55, no. 5, pp. 379-384, 2010.

[65] B. Yazdani-Biuki, H. Stelzl, H. P. Brezinschek et al., "Improvement of insulin sensitivity in insulin resistant subjects during prolonged treatment with the anti-TNF- $\alpha$ antibody infliximab," European Journal of Clinical Investigation, vol. 34, no. 9, pp. 641642, 2004.

[66] A. Gómez-Hernández, Y. F. Otero, N. De Las Heras et al., "Brown fat lipoatrophy and increased visceral adiposity through a concerted adipocytokines overexpression induces vascular insulin resistance and dysfunction," Endocrinology, vol. 153, no. 3, pp. 1242-1255, 2012.

[67] V. Van Harmelen, P. Ariapart, J. Hoffstedt, I. Lundkvist, S. Bringman, and P. Arner, "Increased adipose angiotensinogen gene expression in human obesity," Obesity Research, vol. 8, no. 4, pp. 337-341, 2000.

[68] I. Shimomura, T. Funahashi, M. Takahashi et al., "Enhanced expression of PAI-1 in visceral fat: possible contributor to vascular disease in obesity," Nature Medicine, vol. 2, no. 7, pp. 800-803, 1996.

[69] B. H. Jones, M. K. Standridge, and N. Moustaid, "Angiotensin II increases lipogenesis in 3T3-L1 and human adipose cells," Endocrinology, vol. 138, no. 4, pp. 1512-1519, 1997.

[70] D. V. Chartoumpekis, I. G. Habeos, P. G. Ziros, A. I. Psyrogiannis, V. E. Kyriazopoulou, and A. G. Papavassiliou, "Brown adipose tissue responds to cold and adrenergic stimulation by induction of FGF21," Molecular Medicine, vol. 17, no. 7-8, pp. 736-740, 2011.

[71] E. Hondares, M. Rosell, F. J. Gonzalez, M. Giralt, R. Iglesias, and F. Villarroya, "Hepatic FGF21 expression is induced at birth via PPAR $\alpha$ in response to milk intake and contributes to thermogenic activation of neonatal brown fat," Cell Metabolism, vol. 11, no. 3, pp. 206-212, 2010.

[72] J. Villarroya, R. Cereijo, and F. Villarroya, "An endocrine role for brown adipose tissue?" American Journal of PhysiologyEndocrinology and Metabolism, vol. 305, no. 5, pp. E567-E572, 2013.

[73] E. Hondares, R. Iglesias, A. Giralt et al., “Thermogenic activation induces FGF21 expression and release in brown adipose tissue," Journal of Biological Chemistry, vol. 286, no. 15, pp. 12983-12990, 2011.

[74] E. Nisoli, C. Tonello, and M. O. Carruba, "Nerve growth factor, $\beta_{3}$-adrenoceptor and uncoupling protein 1 expression in rat brown fat during postnatal development," Neuroscience Letters, vol. 246, no. 1, pp. 5-8, 1998.

[75] F. Sornelli, M. Fiore, G. N. Chaldakov, and L. Aloe, "Adipose tissue-derived nerve growth factor and brain-derived neurotrophic factor: results from experimental stress and diabetes," General Physiology and Biophysics, vol. 28, pp. 179-183, 2009.

[76] C. Tonello, A. Giordano, V. Cozzi et al., "Role of sympathetic activity in controlling the expression of vascular endothelial growth factor in brown fat cells of lean and genetically obese rats," FEBS Letters, vol. 442, no. 2-3, pp. 167-172, 1999.

[77] K. Kikuchi-Utsumi, B. Gao, H. Ohinata, M. Hashimoto, N. Yamamoto, and A. Kuroshima, "Enhanced gene expression of endothelial nitric oxide synthase in brown adipose tissue during cold exposure," American Journal of Physiology-Regulatory Integrative and Comparative Physiology, vol. 282, no. 2, pp. R623-R626, 2002. 
[78] T. P. Fitzgibbons, S. Kogan, M. Aouadi, G. M. Hendricks, J. Straubhaar, and M. P. Czech, "Similarity of mouse perivascular and brown adipose tissues and their resistance to diet-induced inflammation," American Journal of Physiology-Heart and Circulatory Physiology, vol. 301, no. 4, pp. H1425-H1437, 2011.

[79] M. T. Ortega, L. Xie, S. Mora, and S. K. Chapes, "Evaluation of macrophage plasticity in brown and white adipose tissue," Cellular Immunology, vol. 271, no. 1, pp. 124-133, 2011.

[80] L. Chang, H. Milton, D. T. Eitzman, and Y. E. Chen, "Paradoxical roles of perivascular adipose tissue in atherosclerosis and hypertension," Circulation Journal, vol. 77, no. 1, pp. 11-18, 2013.

[81] M. Takaoka, H. Suzuki, S. Shioda et al., "Endovascular injury induces rapid phenotypic changes in perivascular adipose tissue," Arteriosclerosis, Thrombosis, and Vascular Biology, vol. 30, no. 8, pp. 1576-1582, 2010.

[82] T. K. Chatterjee, L. L. Stoll, G. M. Denning et al., "Proinflammatory phenotype of perivascular adipocytes: influence of high-fat feeding," Circulation Research, vol. 104, no. 4, pp. 541-549, 2009.

[83] K. Rittig, J. H. Dolderer, B. Balletshofer et al., "The secretion pattern of perivascular fat cells is different from that of subcutaneous and visceral fat cells," Diabetologia, vol. 55, no. 5, pp. 1514-1525, 2012.

[84] J. N. Fain, A. K. Madan, M. L. Hiler, P. Cheema, and S. W. Bahouth, "Comparison of the release of adipokines by adipose tissue, adipose tissue matrix, and adipocytes from visceral and subcutaneous abdominal adipose tissues of obese humans," Endocrinology, vol. 145, no. 5, pp. 2273-2282, 2004.

[85] M. B. Snijder, J. M. Dekker, M. Visser et al., "Associations of hip and thigh circumferences independent of waist circumference with the incidence of type 2 diabetes: the Hoorn study," The American Journal of Clinical Nutrition, vol. 77, no. 5, pp. 11921197, 2003.

[86] C. S. Fox, J. M. Massaro, U. Hoffmann et al., "Abdominal visceral and subcutaneous adipose tissue compartments: association with metabolic risk factors in the Framingham Heart Study," Circulation, vol. 116, no. 1, pp. 39-48, 2007.

[87] A. Gil, C. M. Aguilera, M. Gil-Campos, and R. Cañete, "Altered signalling and gene expression associated with the immune system and the inflammatory response in obesity," British Journal of Nutrition, vol. 98, no. 1, pp. S121-S126, 2007.

[88] R. G. Baker, M. S. Hayden, and S. Ghosh, "NF- $\kappa$ B, inflammation, and metabolic disease," Cell Metabolism, vol. 13, no. 1, pp. 11-22, 2011.

[89] A. Chawla, K. D. Nguyen, and Y. P. S. Goh, "Macrophagemediated inflammation in metabolic disease," Nature Reviews Immunology, vol. 11, no. 11, pp. 738-749, 2011.

[90] S. Nishimura, I. Manabe, M. Nagasaki et al., "CD8+ effector T cells contribute to macrophage recruitment and adipose tissue inflammation in obesity," Nature Medicine, vol. 15, no. 8, pp. 914-920, 2009.

[91] D. L. Crandall, G. J. Hausman, and J. G. Kral, "A review of the microcirculation of adipose tissue: anatomic, metabolic, and angiogenic perspectives," Microcirculation, vol. 4, no. 2, pp. 211232, 1997.

[92] G. J. Blake and P. M. Ridker, "Inflammatory bio-markers and cardiovascular risk prediction," Journal of Internal Medicine, vol. 252, no. 4, pp. 283-294, 2002.

[93] C. Sengenès, A. Miranville, K. Lolmède, C. A. Curat, and A. Bouloumié, "The role of endothelial cells in inflamed adipose tissue," Journal of Internal Medicine, vol. 262, no. 4, pp. 415-421, 2007.
[94] D. Cai, M. Yuan, D. F. Frantz et al., "Local and systemic insulin resistance resulting from hepatic activation of IKK- $\beta$ and NF$\kappa$ B," Nature Medicine, vol. 11, no. 2, pp. 183-190, 2005.

[95] V. Racanelli and B. Rehermann, "The liver as an immunological organ,” Hepatology, vol. 43, no. 2, supplement, pp. S54-S62, 2006.

[96] S. E. Shoelson, J. Lee, and A. B. Goldfine, "Inflammation and insulin resistance," Journal of Clinical Investigation, vol. 116, no. 7, pp. 1793-1801, 2006.

[97] X. Terra, T. Auguet, I. Quesada et al., "Increased levels and adipose tissue expression of visfatin in morbidly obese women: the relationship with pro-inflammatory cytokines," Clinical Endocrinology, vol. 77, no. 5, pp. 691-698, 2012.

[98] F. Gunes, E. Akbal, E. Cakir, O. Akyurek, M. Altunbas, and M. Ozbek, "Visfatin may be a novel marker for identifying stages of essential hypertension in advanced age patients," Internal Medicine, vol. 51, no. 6, pp. 553-557, 2012.

[99] T. Romacho, C. F. Sánchez-Ferrer, and C. Peiró, "Visfatin/ Nampt: an adipokine with cardiovascular impact," Mediators of Inflammation, vol. 2013, Article ID 946427, 15 pages, 2013.

[100] Y.-N. Chae, T.-H. Kim, M.-K. Kim et al., "Beneficial effects of evogliptin, a novel dipeptidyl peptidase 4 inhibitor, on adiposity with increased Ppargcla in white adipose tissue in obese mice," PLoS ONE, vol. 10, no. 12, Article ID e0144064, 2015.

[101] K. Blaslov, T. Bulum, and L. Duvnjak, "Circulating dipeptidyl peptidase-4 activity is associated with insulin resistance in type 1 diabetic patients," Journal of Diabetes and Its Complications, vol. 29, no. 3, pp. 390-394, 2015.

[102] H. Sell, M. Blüher, N. Klöting et al., "Adipose dipeptidyl peptidase- 4 and obesity: correlation with insulin resistance and depot-specific release from adipose tissue in vivo and in vitro," Diabetes Care, vol. 36, no. 12, pp. 4083-4090, 2013.

[103] W. S. D. Silva Júnior, A. F. D. Godoy-Matos, and L. G. KraemerAguiar, "Dipeptidyl peptidase 4: a new link between diabetes mellitus and atherosclerosis?" BioMed Research International, vol. 2015, Article ID 816164, 10 pages, 2015.

[104] M. Ghorbani, T. H. Claus, and J. Himms-Hagen, "Hypertrophy of brown adipocytes in brown and white adipose tissues and reversal of diet-induced obesity in rats treated with a $\beta 3$ adrenoceptor agonist," Biochemical Pharmacology, vol. 54, no. 1, pp. 121-131, 1997.

[105] C. Guerra, P. Navarro, A. M. Valverde et al., "Brown adipose tissue-specific insulin receptor knockout shows diabetic phenotype without insulin resistance," The Journal of Clinical Investigation, vol. 108, no. 8, pp. 1205-1213, 2001.

[106] Y. Kontani, Y. Wang, K. Kimura et al., "UCP1 deficiency increases susceptibility to diet-induced obesity with age," Aging Cell, vol. 4, no. 3, pp. 147-155, 2005.

[107] J. B. Hansen and K. Kristiansen, "Regulatory circuits controlling white versus brown adipocyte differentiation," Biochemical Journal, vol. 398, no. 2, pp. 153-168, 2006.

[108] A. Bartelt, M. Merkel, and J. Heeren, "A new, powerful player in lipoprotein metabolism: brown adipose tissue," Journal of Molecular Medicine, vol. 90, no. 8, pp. 887-893, 2012.

[109] K. J. Williams, "Molecular processes that handle-and mishandle-dietary lipids," The Journal of Clinical Investigation, vol. 118, no. 10, pp. 3247-3259, 2008.

[110] J. E. Hokanson and M. A. Austin, "Plasma triglyceride level is a risk factor for cardiovascular disease independent of high-density lipoprotein cholesterol level: a meta-analysis of population-based prospective studies," Journal of Cardiovascular Risk, vol. 3, no. 2, pp. 213-219, 1996. 
[111] A. D. Mooradian, "Dyslipidemia in type 2 diabetes mellitus," Nature Clinical Practice Endocrinology \& Metabolism, vol. 5, no. 3, pp. 150-159, 2009.

[112] J. M. Fredriksson, H. Nikami, and J. Nedergaard, "Coldinduced expression of the VEGF gene in brown adipose tissue is independent of thermogenic oxygen consumption," FEBS Letters, vol. 579, no. 25, pp. 5680-5684, 2005.

[113] J. R. D. Mitchell, A. Jacobsson, T. G. Kirchgessner, M. C. Schotz, B. Cannon, and J. Nedergaard, "Regulation of expression of the lipoprotein lipase gene in brown adipose tissue," American Journal of Physiology-Endocrinology and Metabolism, vol. 263, no. 3, part 1, pp. E500-E506, 1992.

[114] V. Ouellet, S. M. Labbé, D. P. Blondin et al., "Brown adipose tissue oxidative metabolism contributes to energy expenditure during acute cold exposure in humans," The Journal of Clinical Investigation, vol. 122, no. 2, pp. 545-552, 2012.

[115] I. G. Shabalina, A. Jacobsson, B. Cannon, and J. Nedergaard, "Native UCP1 displays simple competitive kinetics between the regulators purine nucleotides and fatty acids," The Journal of Biological Chemistry, vol. 279, no. 37, pp. 38236-38248, 2004.

[116] O. S. Dallner, E. Chernogubova, K. A. Brolinson, and T. Bengtsson, " $\beta 3$-adrenergic receptors stimulate glucose uptake in brown adipocytes by two mechanisms independently of glucose transporter 4 translocation," Endocrinology, vol. 147, no. 12, pp. 5730-5739, 2006.

[117] H. Nikami, Y. Shimizu, D. Endoh, H. Yano, and M. Saito, "Cold exposure increases glucose utilization and glucose transporter expression in brown adipose tissue," Biochemical and Biophysical Research Communications, vol. 185, no. 3, pp. 1078-1082, 1992.

[118] Q. Hao, R. Yadav, A. L. Basse et al., "Transcriptome profiling of brown adipose tissue during cold exposure reveals extensive regulation of glucose metabolism," American Journal of Physiology-Endocrinology and Metabolism, vol. 308, no. 5, pp. E380-E392, 2015.

[119] G. Ozen, A. Daci, X. Norel, and G. Topal, "Human perivascular adipose tissue dysfunction as a cause of vascular disease: focus on vascular tone and wall remodeling," European Journal of Pharmacology, vol. 766, pp. 16-24, 2015.

[120] N. K. Brown, Z. Zhou, J. Zhang et al., "Perivascular adipose tissue in vascular function and disease: a review of current research and animal models," Arteriosclerosis, Thrombosis, and Vascular Biology, vol. 34, no. 8, pp. 1621-1630, 2014.

[121] A. Omar, T. K. Chatterjee, Y. Tang, D. Y. Hui, and N. L. Weintraub, "Proinflammatory phenotype of perivascular adipocytes," Arteriosclerosis, Thrombosis, and Vascular Biology, vol. 34, no. 8, pp. 1631-1636, 2014.

[122] C. E. Bussey, S. B. Withers, R. G. Aldous, G. Edwards, and A. M. Heagerty, "Obesity-related perivascular adipose tissue damage is reversed by sustained weight loss in the rat," Arteriosclerosis, Thrombosis, and Vascular Biology, vol. 36, no. 7, pp. 1377-1385, 2016.

[123] A. S. Greenstein, K. Khavandi, S. B. Withers et al., "Local inflammation and hypoxia abolish the protective anticontractile properties of perivascular fat in obese patients," Circulation, vol. 119, no. 12, pp. 1661-1670, 2009.

[124] R. Aghamohammadzadeh, R. D. Unwin, A. S. Greenstein, and A. M. Heagerty, "Effects of obesity on perivascular adipose tissue vasorelaxant function: nitric oxide, inflammation and elevated systemic blood pressure," Journal of Vascular Research, vol. 52, no. 5, pp. 299-305, 2016.
[125] E. C. Eringa, W. Bakker, and V. W. M. van Hinsbergh, "Paracrine regulation of vascular tone, inflammation and insulin sensitivity by perivascular adipose tissue," Vascular Pharmacology, vol. 56, no. 5-6, pp. 204-209, 2012.

[126] K. Rittig, K. Staib, J. Machann et al., "Perivascular fatty tissue at the brachial artery is linked to insulin resistance but not to local endothelial dysfunction," Diabetologia, vol. 51, no. 11, pp. 2093-2099, 2008.

[127] S. E. Feldon, C. W. O’Loughlin, D. M. Ray, S. Landskroner-Eiger, K. E. Seweryniak, and R. P. Phipps, "Activated human T lymphocytes express cyclooxygenase- 2 and produce proadipogenic prostaglandins that drive human orbital fibroblast differentiation to adipocytes," The American Journal of Pathology, vol. 169, no. 4, pp. 1183-1193, 2006.

[128] G. A. Payne, L. Borbouse, S. Kumar et al., "Epicardial perivascular adipose-derived leptin exacerbates coronary endothelial dysfunction in metabolic syndrome via a protein kinase C$\beta$ pathway," Arteriosclerosis, Thrombosis, and Vascular Biology, vol. 30, no. 9, pp. 1711-1717, 2010.

[129] E. Henrichot, C. E. Juge-Aubry, A. Pernin et al., "Production of chemokines by perivascular adipose tissue: a role in the pathogenesis of atherosclerosis?" Arteriosclerosis, Thrombosis, and Vascular Biology, vol. 25, no. 12, pp. 2594-2599, 2005.

[130] C. Marchesi, T. Ebrahimian, O. Angulo, P. Paradis, and E. L. Schiffrin, "Endothelial nitric oxide synthase uncoupling and perivascular adipose oxidative stress and inflammation contribute to vascular dysfunction in a rodent model of metabolic syndrome," Hypertension, vol. 54, no. 6, pp. 1384-1392, 2009.

[131] H. S. Sacks and J. N. Fain, "Human epicardial fat: what is new and what is missing?" Clinical and Experimental Pharmacology and Physiology, vol. 38, no. 12, pp. 879-887, 2011.

[132] T. Mazurek, L. Zhang, A. Zalewski et al., "Human epicardial adipose tissue is a source of inflammatory mediators," Circulation, vol. 108, no. 20, pp. 2460-2466, 2003.

[133] L. M. Redman and E. Ravussin, "Endocrine alterations in response to calorie restriction in humans," Molecular and Cellular Endocrinology, vol. 299, no. 1, pp. 129-136, 2009.

[134] A. Howell, M. Chapman, and M. Harvie, "Energy restriction for breast cancer prevention," Recent Results in Cancer Research, vol. 181, pp. 97-111, 2009.

[135] G. López-Lluch, N. Hunt, B. Jones et al., "Calorie restriction induces mitochondrial biogenesis and bioenergetic efficiency," Proceedings of the National Academy of Sciences of the United States of America, vol. 103, no. 6, pp. 1768-1773, 2006.

[136] J. C. Seidell, "Environmental influences on regional fat distribution," International Journal of Obesity, vol. 15, supplement 2, pp. 31-35, 1991.

[137] K. A. Varady, S. Bhutani, M. C. Klempel, and C. M. Kroeger, "Comparison of effects of diet versus exercise weight loss regimens on LDL and HDL particle size in obese adults," Lipids in Health and Disease, vol. 10, article 119, 2011.

[138] W. H. M. Saris, "Effects of energy restriction and exercise on the sympathetic nervous system," International Journal of Obesity, vol. 19, no. 7, pp. S17-S23, 1995.

[139] E. Zorba, T. Cengiz, and K. Karacabey, "Exercise training improves body composition, blood lipid profile and serum insulin levels in obese children," Journal of Sports Medicine and Physical Fitness, vol. 51, no. 4, pp. 664-669, 2011.

[140] B. Lamarche, J.-P. Despres, S. Moorjani et al., "Evidence for a role of insulin in the regulation of abdominal adipose tissue lipoprotein lipase response to exercise training in obese 
women," International Journal of Obesity, vol. 17, no. 5, pp. 255261, 1993.

[141] A. Tremblay, A. Nadeau, J.-P. Després, L. St-Jean, G. Thériault, and C. Bouchard, "Long-term exercise training with constant energy intake. 2: effect on glucose metabolism and resting energy expenditure," International Journal of Obesity, vol. 14, no. 1, pp. 75-84, 1990.

[142] D. Richard, "Cognitive and autonomic determinants of energy homeostasis in obesity," Nature Reviews Endocrinology, vol. 11, no. 8, pp. 489-501, 2015.

[143] S. C. Woods, "The control of food intake: behavioral versus molecular perspectives," Cell Metabolism, vol. 9, no. 6, pp. 489498, 2009.

[144] J. M. Friedman and J. L. Halaas, "Leptin and the regulation of body weight in mammals," Nature, vol. 395, no. 6704, pp. 763770, 1998.

[145] H. Münzberg and C. D. Morrison, "Structure, production and signaling of leptin," Metabolism: Clinical and Experimental, vol. 64, no. 1, pp. 13-23, 2015.

[146] Z. Jovanovic and G. S. H. Yeo, "Central leptin signalling: beyond the arcuate nucleus," Autonomic Neuroscience: Basic and Clinical, vol. 156, no. 1-2, pp. 8-14, 2010.

[147] M. Perello and S. L. Dickson, "Ghrelin signalling on food reward: a salient link between the gut and the mesolimbic system," Journal of Neuroendocrinology, vol. 27, no. 6, pp. 424434, 2015

[148] H. Kirchner, K. M. Heppner, and M. H. Tschöp, “The role of ghrelin in the control of energy balance," Handbook of Experimental Pharmacology, vol. 209, pp. 161-184, 2012.

[149] P. Behary and A. D. Miras, "Brain responses to food and weight loss," Experimental Physiology, vol. 99, no. 9, pp. 1121-1127, 2014.

[150] P. Sumithran, L. A. Prendergast, E. Delbridge et al., "Long-term persistence of hormonal adaptations to weight loss," The New England Journal of Medicine, vol. 365, no. 17, pp. 1597-1604, 2011.

[151] M. Rosenbaum and R. L. Leibel, "Adaptive thermogenesis in humans," International Journal of Obesity, vol. 34, no. 1, pp. S47S55, 2010.

[152] A. Tremblay, M.-M. Royer, J.-P. Chaput, and É. Doucet, "Adaptive thermogenesis can make a difference in the ability of obese individuals to lose body weight," International Journal of Obesity, vol. 37, no. 6, pp. 759-764, 2013.

[153] S. Z. Yanovski and J. A. Yanovski, "Long-term drug treatment for obesity: a systematic and clinical review," The Journal of the American Medical Association, vol. 311, no. 1, pp. 74-86, 2014.

[154] Eisai Inc, "BELVIQ (lorcaserin hydrochloride) tablets, for oral use," Patient Package Insert, 2013, http://www.accessdata.fda .gov/drugsatfda_docs/label/2012/022529lbl.pdf.

[155] Vivus Inc, "Qsymia (phentermine and topiramate extended-release) capsules, for oral use," Patient package, 2013, http://www .accessdata.fda.gov/drugsatfda_docs/label/2013/022580s004lbl .pdf.

[156] G. Derosa and P. Maffioli, "Anti-obesity drugs: a review about their effects and their safety," Expert Opinion on Drug Safety, vol. 11, no. 3, pp. 459-471, 2012.

[157] A. Khan, S. Raza, Y. Khan et al., "Current updates in the medical management of obesity," Recent Patents on Endocrine, Metabolic \& Immune Drug Discovery, vol. 6, no. 2, pp. 117-128, 2012.

[158] P. M. O’Neil, S. R. Smith, N. J. Weissman et al., "Randomized placebo-controlled clinical trial of lorcaserin for weight loss in type 2 diabetes mellitus: the BLOOM-DM study," Obesity, vol. 20, no. 7, pp. 1426-1436, 2012.
[159] K. H. Saunders, R. B. Kumar, L. I. Igel, and L. J. Aronne, "Pharmacologic approaches to weight management: recent gains and shortfalls in combating obesity," Current Atherosclerosis Reports, vol. 18, no. 7, 2016.

[160] A. Cahn and I. Raz, "Emerging gliptins for type 2 diabetes," Expert Opinion on Emerging Drugs, vol. 18, no. 2, pp. 245-258, 2013.

[161] J. P. Lomenick, M. S. Buchowski, and A. H. Shoemaker, "A 52week pilot study of the effects of exenatide on body weight in patients with hypothalamic obesity," Obesity, vol. 24, no. 6, pp. 1222-1225, 2016.

[162] J. Y. Hong, K. Y. Park, B. J. Kim, W. M. Hwang, D. Kim, and D. Lim, "Effects of short-term exenatide treatment on regional fat distribution, glycated hemoglobin levels, and aortic pulse wave velocity of obese type 2 diabetes mellitus patients," Endocrinology and Metabolism, vol. 31, no. 1, pp. 80-85, 2016.

[163] F. Sun, S. Chai, L. Li et al., "Effects of glucagon-like peptide-1 receptor agonists on weight loss in patients with type 2 diabetes: a systematic review and network meta-analysis," Journal of Diabetes Research, vol. 2015, Article ID 157201, 9 pages, 2015.

[164] A. L. P. Harmel, D. M. Kendall, J. B. Buse, P. J. Boyle, A. Marchetti, and H. Lau, "Impact of adjunctive thiazolidinedione therapy on blood lipid levels and glycemic control in patients with type 2 diabetes," Current Medical Research and Opinion, vol. 20, no. 2, pp. 215-223, 2004.

[165] J. Hetzel, B. Balletshofer, K. Rittig et al., "Rapid effects of rosiglitazone treatment on endothelial function and inflammatory biomarkers," Arteriosclerosis, Thrombosis, and Vascular Biology, vol. 25, no. 9, pp. 1804-1809, 2005.

[166] V. Pasceri, H. D. Wu, J. T. Willerson, and E. T. H. Yeh, "Modulation of vascular inflammation in vitro and in vivo by peroxisome proliferator-activated receptor- $\gamma$ activators," Circulation, vol. 101, no. 3, pp. 235-238, 2000.

[167] A. Rubenstrunk, R. Hanf, D. W. Hum, J.-C. Fruchart, and B. Staels, "Safety issues and prospects for future generations of PPAR modulators," Biochimica et Biophysica Acta (BBA)Molecular and Cell Biology of Lipids, vol. 1771, no. 8, pp. 10651081, 2007.

[168] L. Villacorta, F. J. Schopfer, J. Zhang, B. A. Freeman, and Y. E. Chen, "PPAR $\gamma$ and its ligands: therapeutic implications in cardiovascular disease," Clinical Science, vol. 116, no. 3, pp. 205218, 2009.

[169] J. C. Silva, F. A. César, E. M. de Oliveira et al., "New PPAR $\gamma$ partial agonist improves obesity-induced metabolic alterations and atherosclerosis in $\mathrm{LDLr}^{-/-}$mice," Pharmacological Research, vol. 104, pp. 49-60, 2016.

[170] M. Yen and M. B. Ewald, "Toxicity of weight loss agents," Journal of Medical Toxicology, vol. 8, no. 2, pp. 145-152, 2012.

[171] D. Langin, "Adipose tissue lipolysis as a metabolic pathway to define pharmacological strategies against obesity and the metabolic syndrome," Pharmacological Research, vol. 53, no. 6, pp. 482-491, 2006.

[172] S. Enerbäck, "Human brown adipose tissue," Cell Metabolism, vol. 11, no. 4, pp. 248-252, 2010.

[173] D. Langin, "Recruitment of brown fat and conversion of white into brown adipocytes: strategies to fight the metabolic complications of obesity?" Biochimica et Biophysica Acta (BBA)Molecular and Cell Biology of Lipids, vol.1801, no. 3, pp. 372-376, 2010.

[174] A.-L. Poher, J. Altirriba, C. Veyrat-Durebex, and F. RohnerJeanrenaud, "Brown adipose tissue activity as a target for the 
treatment of obesity/insulin resistance," Frontiers in Physiology, vol. 6, article 4, 2015.

[175] S. R. Farmer, "Brown fat and skeletal muscle: unlikely cousins?" Cell, vol. 134, no. 5, pp. 726-727, 2008.

[176] T. J. Schulz, T. L. Huang, T. T. Tran et al., "Identification of inducible brown adipocyte progenitors residing in skeletal muscle and white fat," Proceedings of the National Academy of Sciences of the United States of America, vol. 108, no. 1, pp. 143148, 2011.

[177] C. Weyer, P. A. Tataranni, S. Snitker, E. Danforth Jr., and E. Ravussin, "Increase in insulin action and fat oxidation after treatment with CL 316,243, a highly selective $\beta 3$-adrenoceptor agonist in humans," Diabetes, vol. 47, no. 10, pp. 1555-1561, 1998.

[178] T. M. Larsen, S. Toubro, M. A. Van Baak et al., "Effect of a 28d treatment with L-796568, a novel $\beta$ 3-adrenergic receptor agonist, on energy expenditure and body composition in obese men," American Journal of Clinical Nutrition, vol. 76, no. 4, pp. 780-788, 2002.

[179] L. M. Redman, L. De Jonge, X. Fang et al., "Lack of an effect of a novel $\beta 3$-adrenoceptor agonist, TAK-677, on energy metabolism in obese individuals: a double-blind, Placebo-Controlled Randomized Study," Journal of Clinical Endocrinology and Metabolism, vol. 92, no. 2, pp. 527-531, 2007.

[180] A. M. Cypess, L. S. Weiner, C. Roberts-Toler et al., "Activation of human brown adipose tissue by a $\beta 3$-adrenergic receptor agonist," Cell Metabolism, vol. 21, no. 1, pp. 33-38, 2015.

[181] K. L. Townsend and Y. H. Tseng, "Brown adipose tissue. Recent insights into development, metabolic function and therapeutic potential," Adipocyte, vol. 1, no. 1, pp. 13-24, 2012.

[182] A. Rodríguez, S. Becerril, S. Ezquerro, L. Méndez-Giménez, and G. Frühbeck, "Cross-talk between adipokines and myokines in fat browning," Acta Physiologica, 2016.

[183] D. M. Sepa-Kishi and R. B. Ceddia, "Exercise-mediated effects on white and brown adipose tissue plasticity and metabolism," Exercise and Sport Sciences Reviews, vol. 44, no. 1, pp. 37-44, 2016.

[184] T. L. Rachid, A. Penna-de-Carvalho, I. Bringhenti, M. B. Aguila, C. A. Mandarim-de-Lacerda, and V. Souza-Mello, "Fenofibrate (PPAR $\alpha$ agonist) induces beige cell formation in subcutaneous white adipose tissue from diet-induced male obese mice," Molecular and Cellular Endocrinology, vol. 40, pp. 86-94, 2015.

[185] N. Petrovic, T. B. Walden, I. G. Shabalina, J. A. Timmons, B. Cannon, and J. Nedergaard, "Chronic peroxisome proliferatoractivated receptor $\gamma$ (PPAR $\gamma$ ) activation of epididymally derived white adipocyte cultures reveals a population of thermogenically competent, UCP1-containing adipocytes molecularly distinct from classic brown adipocytes," The Journal of Biological Chemistry, vol. 285, no. 10, pp. 7153-7164, 2010.

[186] T. Coskun, H. A. Bina, M. A. Schneider et al., "Fibroblast growth factor 21 corrects obesity in mice," Endocrinology, vol. 149, no. 12, pp. 6018-6027, 2008.

[187] M. Petruzzelli, M. Schweiger, R. Schreiber et al., "A switch from white to brown fat increases energy expenditure in cancerassociated cachexia," Cell Metabolism, vol. 20, no. 3, pp. 433-447, 2014.

[188] M. Bordicchia, D. Liu, E.-Z. Amri et al., "Cardiac natriuretic peptides act via 38 MAPK to induce the brown fat thermogenic program in mouse and human adipocytes," The Journal of Clinical Investigation, vol. 122, no. 3, pp. 1022-1036, 2012.

[189] L. D. Roberts, P. Boström, J. F. O’Sullivan et al., “ $\beta$-Aminoisobutyric acid induces browning of white fat and hepatic $\beta$-oxidation and is inversely correlated with cardiometabolic risk factors," Cell Metabolism, vol. 19, no. 1, pp. 96-108, 2014.

[190] N. Jeremic, P. Chaturvedi, and S. C. Tyagi, "Browning of white fat: novel insight into factors, mechanisms, and therapeutics," Journal of Cellular Physiology, 2016.

[191] E. Subbotina, A. Sierra, Z. Zhu et al., "Musclin is an activitystimulated myokine that enhances physical endurance," Proceedings of the National Academy of Sciences of the United States of America, vol. 112, no. 52, pp. 16042-16047, 2015.

[192] F. Norheim, T. M. Langleite, M. Hjorth et al., "The effects of acute and chronic exercise on PGC- $1 \alpha$, irisin and browning of subcutaneous adipose tissue in humans," FEBS Journal, vol. 281, no. 3, pp. 739-749, 2014.

[193] B. A. Irving, C. D. Still, and G. Argyropoulos, "Does IRISIN have a BRITE future as a therapeutic agent in humans?" Current Obesity Reports, vol. 3, no. 2, pp. 235-241, 2014.

[194] E. Brailoiu, E. Deliu, R. A. Sporici, and G. C. Brailoiu, "Irisin evokes bradycardia by activating cardiac-projecting neurons of nucleus ambiguus," Physiological Reports, vol. 3, no. 6, Article ID e12419, 2015.

[195] C. Xie, Y. Zhang, T. D. N. Tran et al., "Irisin controls growth, intracellular $\mathrm{Ca}^{2+}$ signals, and mitochondrial thermogenesis in cardiomyoblasts," PLoS ONE, vol. 10, no. 8, Article ID e0136816, 2015.

[196] M. Fernández-Galilea, P. Pérez-Matute, P. L. Prieto-Hontoria et al., " $\alpha$-Lipoic acid treatment increases mitochondrial biogenesis and promotes beige adipose features in subcutaneous adipocytes from overweight/obese subjects," Biochimica et Biophysica Acta-Molecular and Cell Biology of Lipids, vol. 1851, no. 3, pp. 273-281, 2015. 


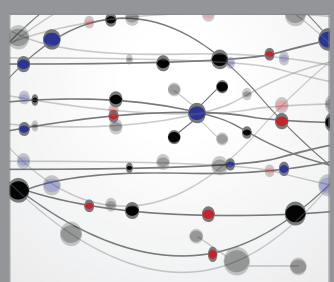

The Scientific World Journal
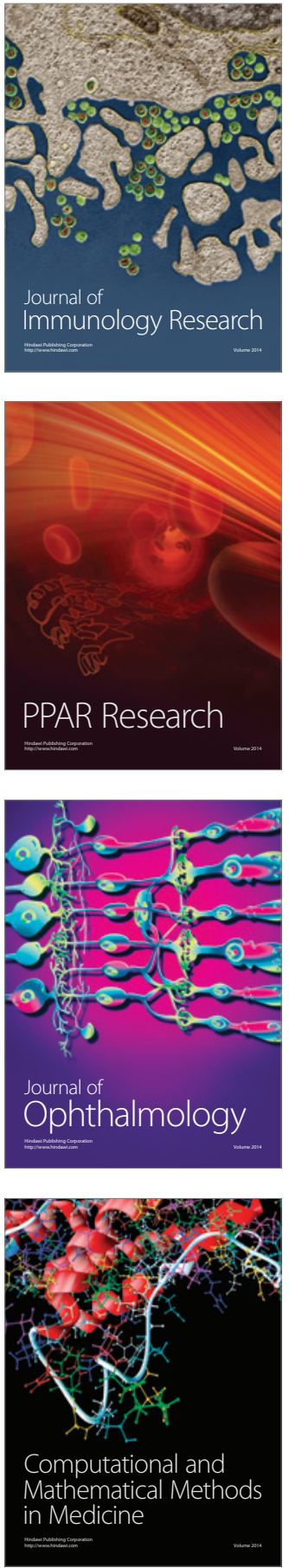

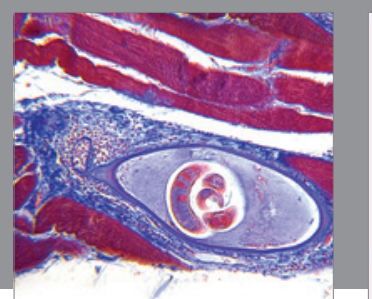

Gastroenterology Research and Practice

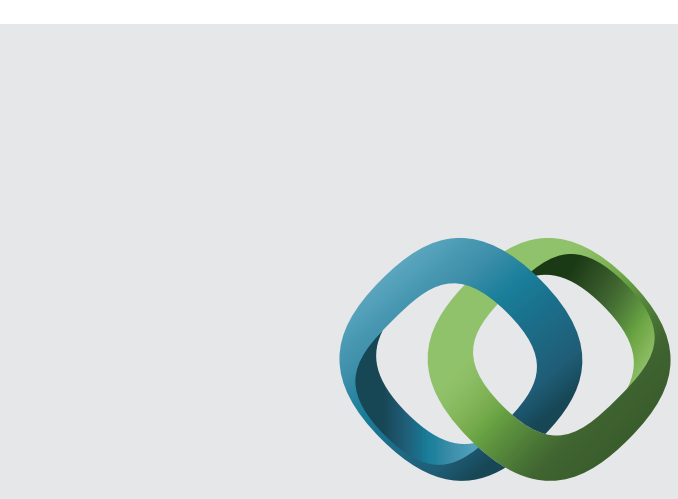

\section{Hindawi}

Submit your manuscripts at

http://www.hindawi.com
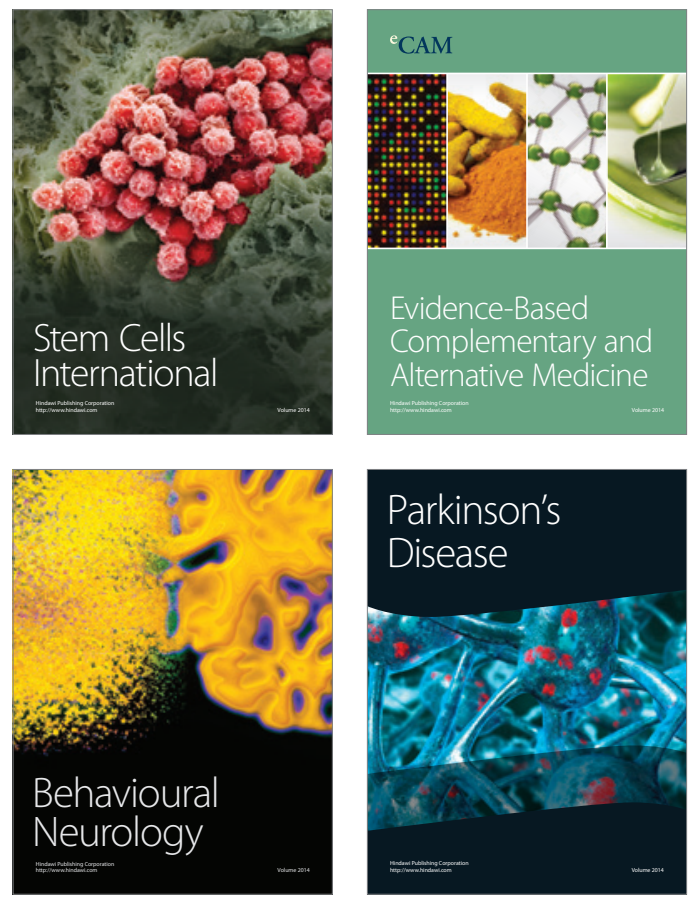
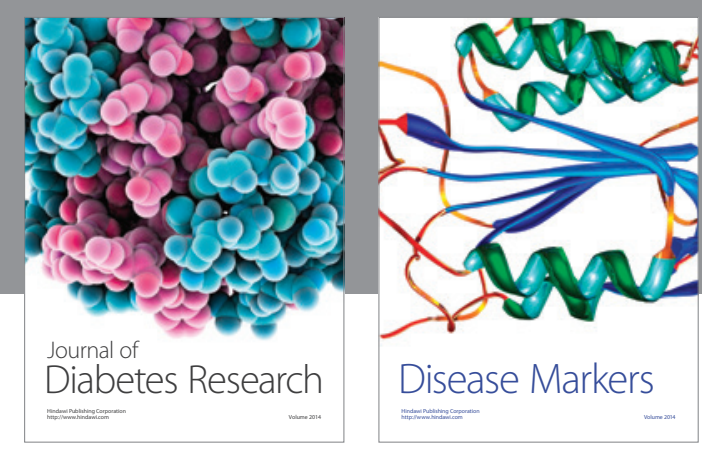

Disease Markers
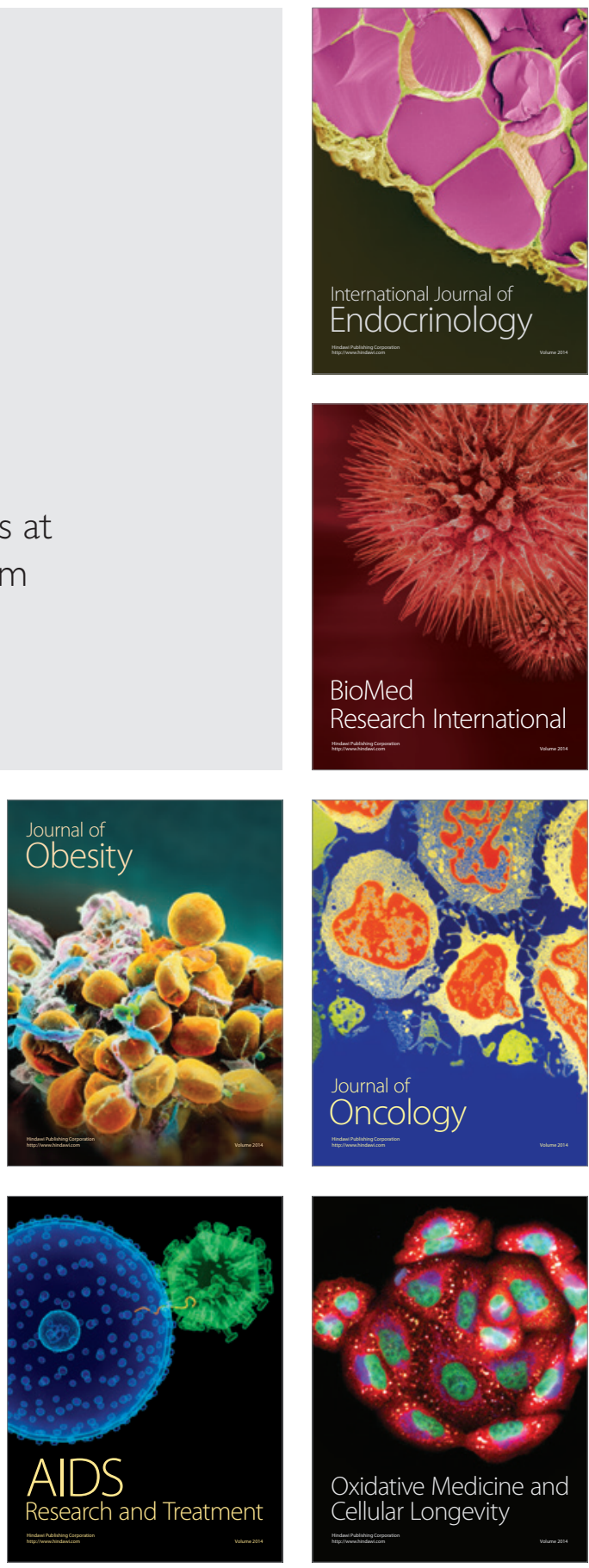